\title{
Double-Layer Learning, Leaders' Forgetting, and Knowledge Performance in Online Work Community Organizations
}

\author{
Wenqing Wu, College of Management and Economics, Tianjin University, China \\ Saixiang Ma, College of Management and Economics, Tianjin University, China \\ Yuzheng Su, College of Management and Economics, Tianjin University, China \\ Chia-Huei Wu, Institute of Service Industries and Management, Minghsin University of Science Technology, Taiwan \\ iD https://orcid.org/0000-0001-6399-2113
}

\begin{abstract}
This paper constructs an online community organizational double-layer learning structure model based on exploration-exploitation models. In this way, the authors examine the effect how doublelayer online community learning as well as heterogeneous teams affects online work community organizational knowledge performance (OWCOKP) with leaders forgetting and without leaders forgetting. First, the results suggest an inverted-U relationship between the degree of different team member connectivity and OWCOKP. Second, as the leaders forgetting rate increases, the degree of different team member connectivity, which leads to the optimum OWCOKP also increases. Third, with or without leaders forgetting, moderate learning between members and that between the leader and members can improve OWCOKP within a team of online community. Fourth, in different teams, slow learning between leaders produces higher OWCOKP without leaders forgetting while moderate learning between leaders produces higher OWCOKP with their forgetting.
\end{abstract}

\section{KEYWORDS}

Double-Layer Learning, Knowledge Learning, Knowledge Performance, Leaders Forgetting, Online Work Community Organization

\section{INTRODUCTION}

With the development of mobile Internet, online work knowledge community (OWKC), as a new organization that can effectively promote innovation, has attracted more and more attention (Hamidi \& Jahanshahifard, 2018; Oh, Moon, Hahn, \& Kim, 2016).Among them, knowledge, as the carrier of innovation and communication, is one of the core contents of research (Zablith, Faraj, \& Azad, 2016). Recently, OWKC emerges more and more as organizations increasingly regard open innovation as important external sources of knowledge and innovation (Piller \& West, 2014; Randhawa, Josserand, Schweitzer, \& Logue, 2017). Organizational learning in online work communities is an important 
channel to create and transfer knowledge, and it is a key factor affecting organizational performance (Berends \& Antonacopoulou, 2014; Chang, Wong, Eng, \& Chen, 2018). There is a positive and significant relationship between organizational learning and organizational innovation in online work community (Hurley \& Hult, 1998; Saki, Shakiba, \& Savari, 2013; Sanz-Valle, Naranjo-Valencia, Jimenez-Jimenez, \& Perez-Caballero, 2011). In complex and changeable environments, organizational learning can enable enterprises to gain competitive advantage through sustainable, healthy and harmonious development (Argote \& Ingram, 2000; Argote \& Miron-Spektor, 2011). Because OWKC has the characteristics of autonomy, spontaneity, mutuality and shared identities among members (Dahlander \& Frederiksen, 2012; West, Salter, Vanhaverbeke, \& Chesbrough, 2014), how to manage organizational learning in OWKC has become an important issue. Some empirical studies showed that the degree centrality and members' social interactions of online community members had a significant positive effect on knowledge sharing and organizational learning (J. Fang, Chen, Wang, \& George, 2018), however, centralized structure of communication is not associated with the collaboration performance (Lee, Jang, \& Baek, 2019).

There are many types of organizational learning, two of which are exploitative learning and exploratory learning (Li, Lin, Cui, \& Qian, 2018). March (1991) posed the concepts of exploration and exploitation in relation to organizational learning. Since March's classical exploration-exploitation model was created, researchers had discussed the balance between exploration and exploitation from different perspectives, such as organizational structure (e.g., Bunderson \& Boumgarden, 2010). The balancing of exploration and exploitation through structural design has been given considerable attention (e.g., C. Fang, Lee, \& Schilling, 2010; Schilling \& Fang, 2014). However, most previous studies have focused on a single-layer structure between individuals in an organization; specifically, in their simulation models, previous studies treat individuals within an organization as a homogeneous group, neglecting the different roles that individuals (such as leaders and members) play within an organization. There is little focus on multi-layer structures and multi-level learning between individuals in an organization. The aim of our study is thus to contribute to filling this gap in the literature on organizational learning.

In addition to organizational learning, forgetting has also been examined by various researchers. Managing organizational learning and knowledge must also include efforts to understand and manage forgetting (Holan \& Phillips, 2013). Brunsson (1998) proposed that it might also help organizations to unlearn (forget). Organizational forgetting may lead to the ability of an organization to innovate and may even directly impact the organization's survival (Huang, Chen, Zhang, \& Ye, 2018). With continuous organizational development, it must also be considered whether the original knowledge owned by an organization is useful for the present (Hislop, Bosley, Coombs, \& Holland, 2014; Martinez-Plumed, Ferri, Hernandez-Orallo, \& Ramirez-Quintana, 2015). For example, if the existing knowledge is extraneous or is actively interfering with the application of more appropriate knowledge, forgetting is a positive occurrence (Holan \& Phillips, 2013; Wu, Ma, Wang, Tsai, \& Lin, 2019). Therefore, investigating the effect of knowledge forgetting on online work community knowledge performance (OWCOKP) is very important. Drawing on this, our study combines organizational learning and forgetting to examine the joint influence of them on OWCOKP.

This paper focuses on the problem of how multi-layer structures and multi-level learning between individuals in an online work community organization influence OWCOKP. In addition, in the multilayer structures of an online work community organization, the role of leaders, who guide organizations, identify environmental needs, and facilitate appropriate development, is very important (Waddell \& Pio, 2015). Therefore, we emphasize the role of leaders and mainly examine how leaders' forgetting in multi-layer structures affects OWCOKP. We thus investigate the effect of double-layer learning on OWCOKP in two situations: with leaders' forgetting and without leaders' forgetting. We construct an organizational double-layer learning structure model using computer simulation methods to investigate these problems. Our study contributes to online work community organizational learning in two main ways. First, by constructing an online work community organizational double-layer learning 
structure model, we study multi-level learning within teams and across different teams. Second, we add leaders' forgetting to our double-layer learning structure model, and we compare the multi-level learning process within an online work community organization in two situations: with leaders' forgetting and without leaders' forgetting.

In the next section, we review the related literature on organizational learning, organizational structure and forgetting. We also present the details of the literature search on exploration-exploitation models. After that, based on these exploration-exploitation models, we describe the construction of the organizational double-layer learning structure model by simulation methods. The simulation results are shown in the fourth section. We explain the process of multi-level learning within teams and across different teams in two situations: with leaders' forgetting and without leaders' forgetting. The final section of the article discusses our contributions to online work community organizational learning, theoretical and managerial implications and research directions.

\section{THEORETICAL BACKGROUND}

\section{The Context of Organizational Learning}

As mentioned in the previous section, organizational learning can enable firms to access the managerial capabilities and technological know-how necessary to compete in a global economy (Harrison \& Leitch, 2005). Effective organizational learning activities can help firms in transitional economies reduce uncertainty and find market opportunities more quickly in order to compete more effectively (Zhao, Li, Lee, \& Chen, 2011). Over the past few decades, researchers have extensively investigated various aspects of organizational learning. Sharpanskykh and Stroeve (2011) pointed that organizational learning could be defined from the adaptation and knowledge perspectives. From the adaptation perspective, organizational learning is defined as the process of organizational adaptation to internal or external changes based on individual learning. From the knowledge perspective, organizational learning is defined as accumulation of organizational knowledge. In addition, Choi, Park, and Lee (2015) concluded that studies on organizational learning mainly focused on the following five aspects. The first stream of research focuses on how organizational learning is affected by the characteristics of knowledge itself, such as explicit vs. tacit (e.g., Ikujiro Nonaka, 1994; I. Nonaka \& Von Krogh, 2009). The second stream emphasizes the mode of learning, such as exploration vs. exploitation (e.g., March, 1991). The third stream examines the procedural aspects of organizational learning behaviour, such as the search, creation, transfer and retention of knowledge (e.g., Cohen \& Levinthal, 1990; Gupta, Tesluk, \& Taylor, 2007; Knudsen \& Levinthal, 2007; Moorman \& Miner, 1997). The fourth stream centres on how learning is affected by organizational characteristics, such as structure (e.g., Bunderson \& Boumgarden, 2010; C. Fang et al., 2010). The last stream grapples with the question of how environmental conditions, such as the level of uncertainty, affect organizational learning (e.g., Daft \& Weick, 1984).

\section{Exploration and Exploitation}

The mode of organizational learning has a significant effect on organizational knowledge performance (OKP). Exploration and exploitation are important modes of organizational learning, and the balancing of exploration and exploitation has been paid considerable attention. March (1991) proposed a classical exploration-exploitation model in which slow learning refers to exploration and fast learning refers to exploitation. He noted that exploration produces higher OKP in the long run, whereas exploitation quickly improved OKP in the short run. March highlighted the importance of balancing exploration and exploitation and examined the mutual learning between the organizational code and individuals. Miller, Zhao, and Calantone (2006) extended March's model by adding interpersonal learning. Their results highlighted the importance of interpersonal learning and suggested that the intermediate rate of learning from local search produced the most knowledge, while learning from distant search had 
little effect on equilibrium knowledge. Liao, Jiang, and Wang (2011) extended the March's model and compared the effectiveness of the codification and personalization knowledge management strategies. They found that codification strategy could improve knowledge rapidly while personnel strategy can reach higher knowledge level more slowly. T. Kim and Rhee (2009) extended March's explorationexploitation model by (1) conceptualizing and varying two dimensions - amplitude and frequency - of environmental dynamism and (2) articulating the notion of internal variety in an organization. $\mathrm{Xu}$, Liu, and Liu (2014) introduced individual bias to the exploration-exploitation simulation model. They examined the joint effects of individual bias and other factors and their results suggested that individual bias had both positive and negative effects. Employing a multi-agent simulation method, Chae, Seo, and Lee (2015) argued that managers had to properly facilitate either exploration or exploitation depending on task difficulty by striking a balance between them. Chanda and Ray (2015) studied the mix of exploration and exploitation based on March's model. They found that multiple exploration-exploitation combinations leaded to equivalent and maximum organizational knowledge. Uotila (2013) simulated how exploration and exploitation contributed to variability in organizational performance. He argued that although exploration provided more variation within the organization, exploitation could increase performance variation between different organizations.

\section{Organizational Structure}

Organizational structure plays an important role in organizational learning. The types of resources that can be acquired from a network structure depend on the structure of network relations (Adler \& Kwon, 2002; H. Kim, 2019). Knowledge acquisition is affected by organizational structure, which has a significant effect on OKP (Pham, Tran, Thipwong, \& Huang, 2019). Therefore, many researchers have paid attention to organizational structure. Miller et al. (2006) extend March's model by adding interpersonal learning. In their extended model, organizational members are situated in a grid without edges. Using a simulation model, Lazer \& Friedman (2007) studied four typical organizational networks: linear networks, totally connected networks, random networks and small-world networks. C. Fang et al. (2010) examined the balance between exploration and exploitation through structural design. Their results suggested that an organization divided into semi-isolated groups might be able to strike this balance. Zhang and Xi (2012) examined how the interaction of network structure with agent behaviour affected knowledge processes and group performance, and they compared a preferentially attached network and a regular network in their experiment. Schilling and Fang (2014) posited that the interpersonal network structure of an organization directly influenced the diffusion and recombination of ideas and could thus facilitate or impede organizational learning. They found that moderately hubby networks outperformed both very hubby and democratic networks. Previous studies have regarded individuals in an organization as equal in their simulation models and have discussed organizational structures based on this perspective. However, individuals play different roles in an organization (such as leaders and members). The network structures between individuals who have different roles are also different in organizations. In addition, there may be many teams or groups that play different roles in organizations. The network structures between individuals within a team or a group and those between different teams or groups are also different in organizations. Wong (2008) investigated how internal and external advice network structures influenced knowledge overlap and variety and how these knowledge dimensions in turn influenced group effectiveness. Choi et al. (2015) suggested organizational hierarchy as a critical barrier to learning and theoretically explored how it could deter learning performance. They showed that non-hierarchical organizations might be a better learning environment than hierarchical organizations. In addition to simulation model studies, many empirical studies have been conducted based on the research on organizational structure. Jansen, Van den Bosch, and Volberda (2006) examined how formal and informal organizational structures coordinated the development of exploratory and exploitative innovation in organizational units. Mason, Jones, and Goldstone (2008) examined how different network structures affected the propagation of information in laboratory-created groups. They compared different types of networks in terms 
of the speed of discovery and convergence on the optimal solution. Bunderson and Boumgarden (2010) considered the effect of team structure on a team's engagement in learning and continuous improvement. Their study suggested that "bureaucratic" teams can be better learners.

\section{Forgetting}

As mentioned above, forgetting also plays an important part in an organization (Aydin \& Gormus, 2015; Holan \& Phillips, 2004a; Martinez-Plumed et al., 2015). Similar to organizational learning, forgetting has been regarded as a means of promoting change in organizations (Brunsson, 1998; Hislop et al., 2014). The complexity of the external environment causes a business, which does not forget outdated practices, to lose dynamism needed to remain vibrant and competitive (Huang et al., 2018). Competitiveness is not just about learning; it is also about forgetting the outdated things at the right times adapt to various environmental changes. Unneeded and old stocks of knowledge require expensive management and can consume critical management attention, leading to a loss of competitiveness (Derbinsky \& Laird, 2013; Holan \& Phillips, 2004a). Ikujiro Nonaka and Takeuchi (1996) argued that organizational forgetting was a process of relearning, in which new knowledge structures replaced old knowledge structures. Huang et al. (2018) thought that forgetting was a process of abandoning outdated routines, norms, beliefs, procedures, policies, values and methods, while acquiring and assimilating new suitable ones. Blaschke and Schoeneborn (2006) added forgetting to March's model (1991). Based on this simulation model, they examined the effect of individuals forgetting and organizational code forgetting on knowledge. Miller and Martignoni (2016) extended the model of Miller et al. (2006) by adding forgetting. They noted that organizations needed not sacrifice diversity as they gained knowledge, and their results indicated that knowledge and diversity were positively correlated with forgetting across organizations. In addition to simulation model studies, many empirical studies have also been conducted based on the research on forgetting. Huang et al. (2018) investigated 320 Chinese enterprises and demonstrated that the effect of organizational forgetting was not constantly positive but instead increases with the level of environmental turbulence. Based on two case studies in higher education, Fernandez and Sune (2009) concluded that forgetting was a key factor of innovation and closely related to innovation. Aydin and Gormus (2015) compared two coaching companies and examine the role of organizational forgetting in different type of coaching companies. They found that the type of organization had a different type of organizational forgetting and forgetting was very important for organizational survival.

\section{THE MODEL}

Our model is principally built to investigate the effect of double-layer learning on OWCOKP in two situations: with leaders' forgetting and without leaders' forgetting. These are investigated using the agent-based simulation approach. The agent-based simulation approach can not only simulate complex phenomena (Secchi \& Gullekson, 2016), but also examine the interactions between heterogeneous individuals, which is difficult to capture in the empirical study using real data (Guechtouli, Rouchier, \& Orillard, 2013; Xiong, Payne, \& Kinsella, 2016). The agent-based simulation approach is on the rise in online work community (Secchi \& Gullekson, 2016). Therefore, to conduct our study, we use the agent-based simulation approach and carefully consider and design each part of our simulation model. On the one hand, each part of our model is based on related research (Holan \& Phillips, 2004b; Jansen et al., 2006; Mason et al., 2008); on the other hand, we extend traditional explorationexploitation simulation models (C. Fang et al., 2010; March, 1991; Miller \& Martignoni, 2016) but make our model much simpler than these traditional models. More specifically, our model builds on two important facts that have been widely demonstrated in related research: (1) organizational structure has an influence on organizational learning (Bunderson \& Boumgarden, 2010; Lazer \& Friedman, 2007; Schilling \& Fang, 2014), and, (2) similar to organizational learning, forgetting has been regarded 
as a means of promoting change in organizations (Aydin \& Gormus, 2015; Fernandez \& Sune, 2009; Huang et al., 2018). The precise specification of the model is described in the following section.

\section{Model Specification}

1. External Environment: According to March's model, we assume that the external environment has $m$ dimensions in online work community, each of which is assigned a value of 1 or -1 with an equal probability of 0.5 .

2. Teams and Structure: This paper divides individuals in online work community into two layers: leaders and members. Specifically, we assume that there are $t$ teams in an online work community organization, and every team consists of a leader and $n$ members. The knowledge (or belief) vector of the leader and members in each team corresponds to the external environment vector, and it has $m$ dimensions, each of which has a value of 1,0 or -1 with equal probability. The role of a leader is often to understand and utilize the existing knowledge base and structure, and this role is usually assigned to the person who is believed to possess the best available knowledge set (Carley, 1992). Choi et al. (2015) modeled vertical learning where leaders were the highest-performing individuals in their groups and served as the main source of knowledge. In other words, in their model, members only learned knowledge from leaders. By contrast, our model considers mutual learning between members and mutual learning between leaders and members in online work community. Therefore, we argue that the leader's knowledge level (KL) is the highest on each team during the model initialization phase. Notably, the leader's KL is the highest on each team at the beginning of our simulation, but, as the simulation continues, some members' KLs may be higher than that of the leader of each team because members can learn knowledge not only from the leader but also from other members in our model.

Previous studies have shown that organizational structure has an important effect on organizational performance (e.g., C. Fang et al., 2010; Schilling \& Fang, 2014). Therefore, we fully consider the characteristics of the multi-level learning between team leaders and members in an online work community organization and construct an online work community organizational double-layer learning structure model. Specifically, within a team, the leader is connected with each member, and each member is connected with other members. In different teams, a team's leader is connected to other teams' leaders. However, a team's members are connected with other teams' members randomly with probability $r$. Each member within a team can learn knowledge from other teams' members, and then, they can diffuse knowledge to other members within a team. Therefore, to research conveniently but without a loss of generality, we describe the double-layer learning structure model below. In the model, we assume that one member of each team connects to other teams' members and not that all members of each team are connected to other teams' members. Figure 1 shows the simplified online work community organizational double-layer learning structure.

(The actual model has 20 teams, and each team has 1 leader and 10 members. However, for visual clarity, a simplified model is shown here.)

In particular, we assume that a team's members are connected with other teams' members randomly with probability $r(r \in[0,1])$. Different values of $r$ represent different degrees of different teams' member connectivity. When $r=0$, there is no connection between different team members. With the increase in the value of $r$, the connections between different team members gradually increase; when $r=1$, members of each team are connected to other teams' members. Figure 2 shows the different networks between different team members.

(The actual model has 20 teams, and each team has 10 members. However, for visual clarity, a simplified model is shown here.) 


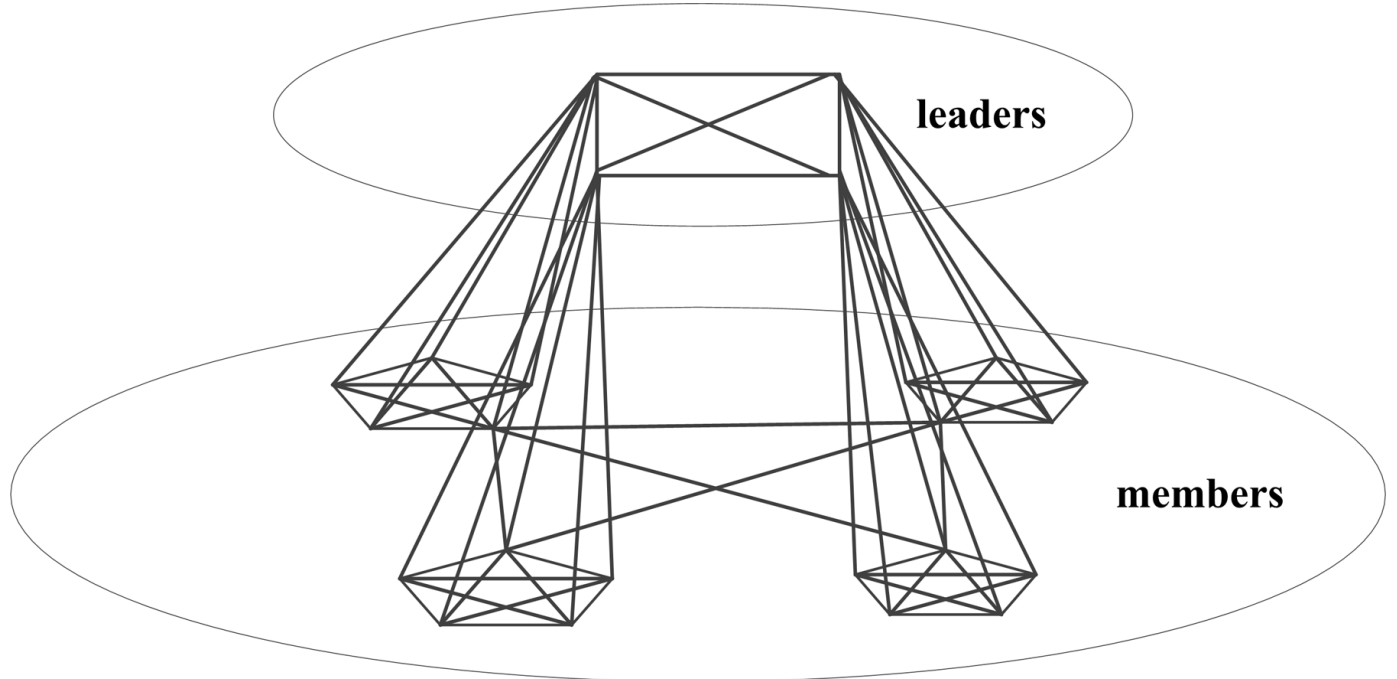

Figure 2. The different networks between different team members
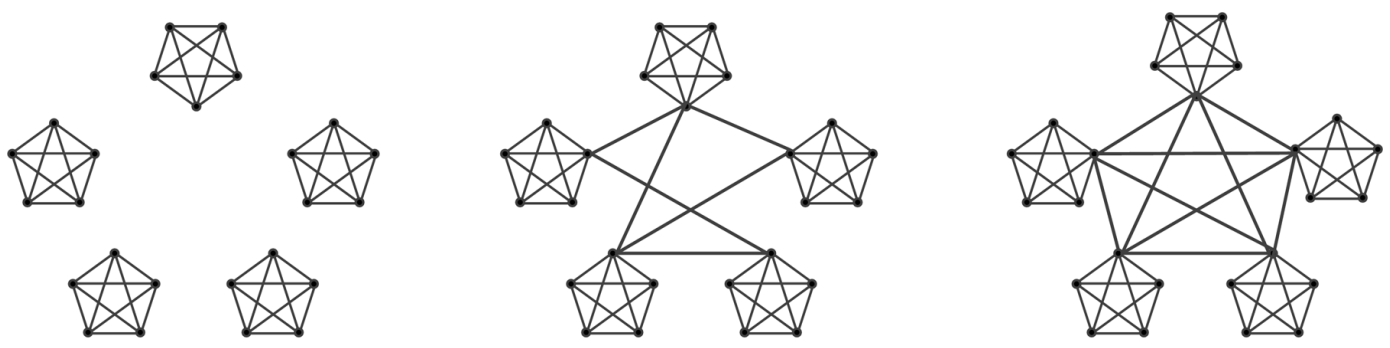

$$
r=0
$$

$r=1$

3. Knowledge Learning: Based on Miller et al. (2006) research and the organizational double-layer learning structure model, we assume that online work community organizational team learning includes the learning within a team and the learning between different teams. Specifically, within a team, the team leader and members learn knowledge from one another. That is, the team leader learns from team members, and team members learn from the leader. Moreover, team members learn from one another. Across different teams, a team leader learns from other team leaders. Different from leaders, team members learn only from other teams' members who connect to them.

4. Forgetting: Miller and Martignoni (2016) assumed that converting a nonzero belief (1 or -1) of the individual knowledge vector to a zero belief ( 0 ) was forgetting. As mentioned above, the leader plays an important role on a online work community team. Therefore, this paper uses Miller and Martignoni's definition of forgetting as a reference and mainly studies the effect of team leaders' forgetting on OWCOKP in the double-layer learning structure. Specifically, we suppose that every team leader converts a nonzero belief (1 or -1$)$ of his knowledge vector to a zero belief ( 0$)$ with probability $f$ in every period. 
5. Knowledge Level (KL): This paper adopts the following method outlined by Fang et al. (2010). This method considers that knowledge is not completely independent, and it perfectly reflects the complexity of knowledge:

$$
\Phi(x)=k\left(\prod_{j=1}^{k} \delta_{j}+\prod_{j=k+1}^{2 k} \delta_{j}+\cdots+\prod_{j=m-k+1}^{m} \delta_{j}\right)
$$

In this function, $m$ is the dimension of the external environment and the knowledge vector; $k$ is the knowledge complexity, and we fix $k=3$ in this paper. $\Phi(x)$ is individuals' KL, and the value of $\delta_{j}$ is 0 or 1 . If an individual knowledge vector corresponds to the external environment vector on the corresponding dimension, $\delta_{j}$ is 1 ; otherwise, $\delta_{j}$ is 0 .

By calculating the arithmetic mean value of team leaders' and members' KL, we evaluate the KL of a team and then calculate the arithmetic mean value of the KL of all teams to estimate OWCOKP.

\section{Simulation Process and Parameters}

1. Learning within a team. In an online work community organization, teams' internal learning includes learning between the team leader and members and the learning between members. Because each member is connected with other members in each team, each member's KL will be compared with other members' KL. That is, a link between two members indicates that the two members are sources of learning for one another. The three possible results are the same $\mathrm{KL}$, higher KL or lower KL. If members make sure that the KLs of other members are higher, they will update their knowledge to incorporate aspects of this higher knowledge with probability $p_{1}$. If there is more than one member whose $\mathrm{KL}$ is higher, we adopt a majority decision rule similar to that used in March's model (1991). The majority decision rule is that members look at all other members with whom they are connected and identify those who perform better than they do. Then, the focal member identifies the dominant knowledge vector on each of $m$ dimensions of these higher-performing members' knowledge. After that, the focal member updates his own knowledge with probability $p_{1}$.

While online work community members' knowledge learning is constant, leaders' knowledge learning is periodical. Jr, Graen, and Haga (1975) posited that leaders treated all subordinates in a uniform manner, independent of their personality, attitudes, and abilities. Oh et al. (2016) proposed that the leader interacts with members with equal frequency under uniform leader-member exchange (ULMX). Therefore, we presume that leaders interact with members of the same team and the leaders of other teams at every period $\alpha$. In other words, at every period $\alpha$, leaders first learn knowledge from members of the same team. Similar to the knowledge learning among members in a team, that between a team's leader and its members also has three possible results: the same KL, higher KL or lower KL. If a leader finds that the KL of a member of the same team is higher, he or she will update his or her knowledge to incorporate aspects of the higher-knowledge individual with probability $p_{2}$. If there is more than one member whose $\mathrm{KL}$ is higher, the majority decision rule will also be used with probability $p_{2}$. After leaders learn knowledge, members begin to learn knowledge from their own leaders. Because a leader is connected with all members on a team, each member's KL will be compared to that of the leader. If members find that their team leader's KL is higher, they will update their knowledge to incorporate aspects of the higher-knowledge leader with probability $p_{3}$. 
2. Learning between different teams. This includes learning between different teams' leaders and learning between different teams' members in an online work community organization. The processes of learning between different teams' members and between members on a team are the same. Different teams' members update their knowledge with probability $p_{4}$. The learning between different teams' leaders is the same. Leaders update their knowledge with probability $p_{5}$.

3. Forgetting. In this paper, we mainly study leaders' forgetting in relation to the learning between different teams' leaders in an online work community organization. Therefore, as mentioned in the previous section, we suppose that every team leader converts a nonzero belief (1 or -1$)$ of his knowledge vector to a zero belief ( 0$)$ with probability $f$ in every period.

All simulation parameters of this paper are shown in Table 1.

Table 1. Parameters for simulation

\begin{tabular}{|c|c|c|}
\hline Parameter & Meaning & Value \\
\hline$m$ & The dimension of external environment and knowledge vector & 60 \\
\hline$t$ & The number of teams and leaders & 20 \\
\hline$n$ & The number of members in each team & 10 \\
\hline$k$ & Knowledge complexity & 3 \\
\hline$r$ & The probability of connection between different teams' members & {$[0,1]$} \\
\hline $\boldsymbol{p}_{1}$ & The rate of members' learning from one another in a team & $0.1,0.3,0.5,0.7,0.9$ \\
\hline $\boldsymbol{p}_{2}$ & The rate of the leader's learning from members in a team & $0.1,0.3,0.5,0.7,0.9$ \\
\hline$p_{3}$ & The rate of members' learning from the leader in a team & $0.1,0.3,0.5,0.7,0.9$ \\
\hline $\boldsymbol{p}_{4}$ & The rate of members' learning from other teams' members & $0.1,0.3,0.5,0.7,0.9$ \\
\hline $\boldsymbol{p}_{5}$ & The rate of leaders' learning from one another & $0.1,0.3,0.5,0.7,0.9$ \\
\hline$f$ & The rate of leaders' forgetting & $0,0.05,0.1$ \\
\hline$\alpha$ & The period of leaders' personal learning & 5 \\
\hline
\end{tabular}

\section{ANALYSIS OF THE SIMULATION AND RESULTS}

We construct the simulation model using MATLAB. To avoid result deviation caused by a single simulation and to ensure the accuracy of the simulation results, we repeat the simulation process 100 times and then calculate the arithmetic mean of the 100 simulation results. All images below show the arithmetic mean of the 100 simulation results. More specifically, because our key variables of focus are the double-layer learning structure and leaders' forgetting, we hold other variables constant in all simulations: $m=60, t=20, n=10, k=3$, and $\alpha=5$. We also vary these variables to investigate 
Figure 3. Effects of the degree of different teams' member connectivity on OKP (Other parameters setting: $p_{1}=0.5, p_{2}=0.5$, $p_{3}=0.5, p_{4}=0.5, p_{5}=0.5$. In this paper, we adopt the default values of learning probabilities used by Miller and Zhao (2006).)

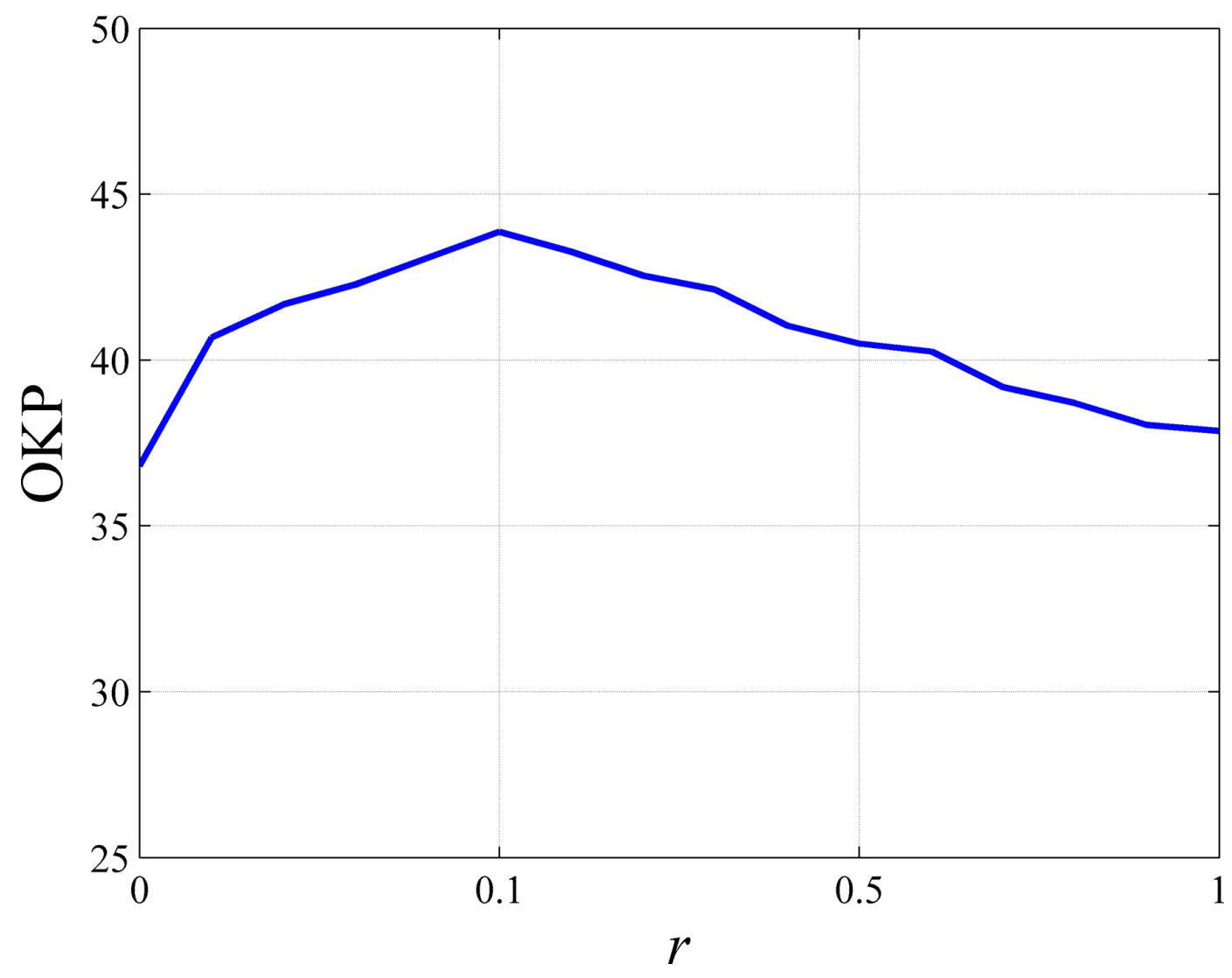

whether they affect our main findings, but we find no substantive change in our results. Details are available in the following sections.

\section{Without Leaders' Forgetting}

First, we study the effect of the double-layer learning structure on OWCOKP without leaders' forgetting. In this section, the rate of leaders' forgetting is held constant, and $f=0$. The simulation results and analysis are as follows.

Figure 3 illustrates the effect of the degree of different teams' member connectivity on OWCOKP. The results in Figure 3 are obtained by simulating the model until it achieves a long-run equilibrium OWCOKP. The results show that as the probability of connection between different teams' members increases in an online work community organization, OWCOKP initially increases and then decreases. In other words, the result suggests that there is an inverted-U relationship between the degrees of different teams' member connectivity and OWCOKP.

Figure 3 shows that both very low and very high values of $r$ (the probability of connection between different teams' members) are low performing, and a moderate value of $r$ can result in the optimum OWCOKP. In this paper, different values of $r$ represent different network densities between different teams' members. The value of $r$ and the network density are positively correlated. Previous studies have suggested that a dense network improves the diffusion of knowledge, which positively 
Figure 4. The relationship between network density and knowledge performance

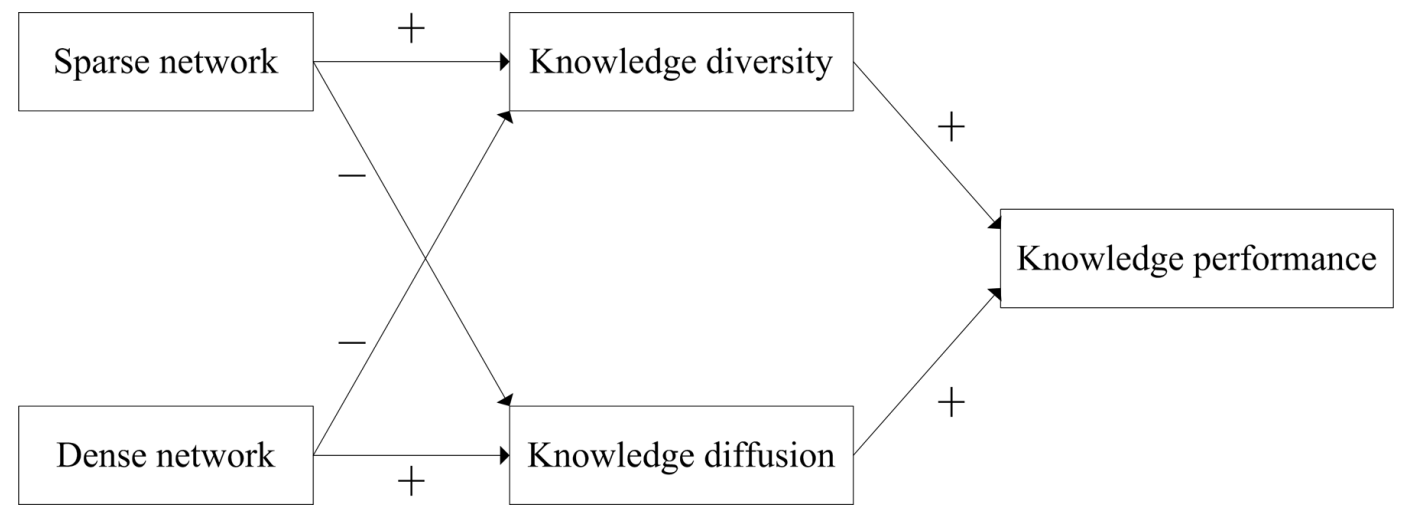

affects OWCOKP. A sparse network can keep knowledge diverse, which is also positively related to OWCOKP (C. Fang et al., 2010; Lazer \& Friedman, 2007). These relationships are depicted in Figure 4 (Lazer \& Friedman, 2007). When there are no or very few connections between different teams' members ( $r$ is very low), teams can maintain their own knowledge diversity. However, with very few connections between different teams' members, good knowledge cannot be effectively shared or exchanged among teams. As such, even if knowledge diversity is preserved, teams cannot benefit from this diversity if there are too few cross-team connections in an online work community organization. When there are too many connections between different teams' members ( $r$ is very high), knowledge can be effectively diffused among teams. However, this may drive out knowledge diversity quickly, which has a negative effect on OWCOKP. Moderate connections between different teams' members not only maintain team knowledge diversity longer but also help diffuse diverse knowledge among teams; this can improve OWCOKP.

Above, we study the effect of the degree of different teams' member connectivity on OWCOKP; next, we study the effect of the rate of leaders' and members' learning on OWCOKP. Given the inverted-U relationship between the degree of different teams' member connectivity and OWCOKP, we consider the effect of the rate of leaders' and members' learning on OWCOKP when the optimum OWCOKP is achieved. According to Figure 3, when $r$ is 0.1 , OWCOKP is highest. Therefore, we set the value of $r$ as 0.1 and then study the effect of the rate of leaders' and members' learning on OWCOKP. The simulation results and analysis are as follows.

Figure 5 shows the effect of the learning between members on OWCOKP within a team. Figure 6 and Figure 7 illustrate the effect of learning between the team leader and members on OWCOKP within a team.

Figure 5, Figure 6 and Figure 7 show that within a team, with the increase in the rate of the learning between the team leader and members and that of the learning between members, the equilibrium OWCOKP first increases and then decreases. Moreover, the period of equilibrium OWCOKP decreases gradually. The results suggest that strengthening the learning between members and the learning between the leader and members can improve OWCOKP. However, it is not a high rate but a moderate rate of learning that leads to higher OWCOKP.

Within a team, members' learning knowledge from other members slowly can maintain team knowledge diversity. However, learning slowly has a negative effect on the diffusion of knowledge. In contrast, members' learning knowledge from other members quickly can spread knowledge effectively within a team. However, this will quickly make team knowledge homogeneous, which results in the loss of team knowledge diversity. Learning too slowly or too quickly is not conducive to improving OWCOKP. A moderate rate of learning between members not only maintains team knowledge diversity longer but also helps diffuse diverse knowledge within a team; this can improve OWCOKP. 
Figure 5. Effects of members' learning from one another on OKP within a team (Other parameters setting: $p_{2}=0.5, p_{3}=0.5$, $\left.p_{4}=0.5, p_{5}=0.5\right)$

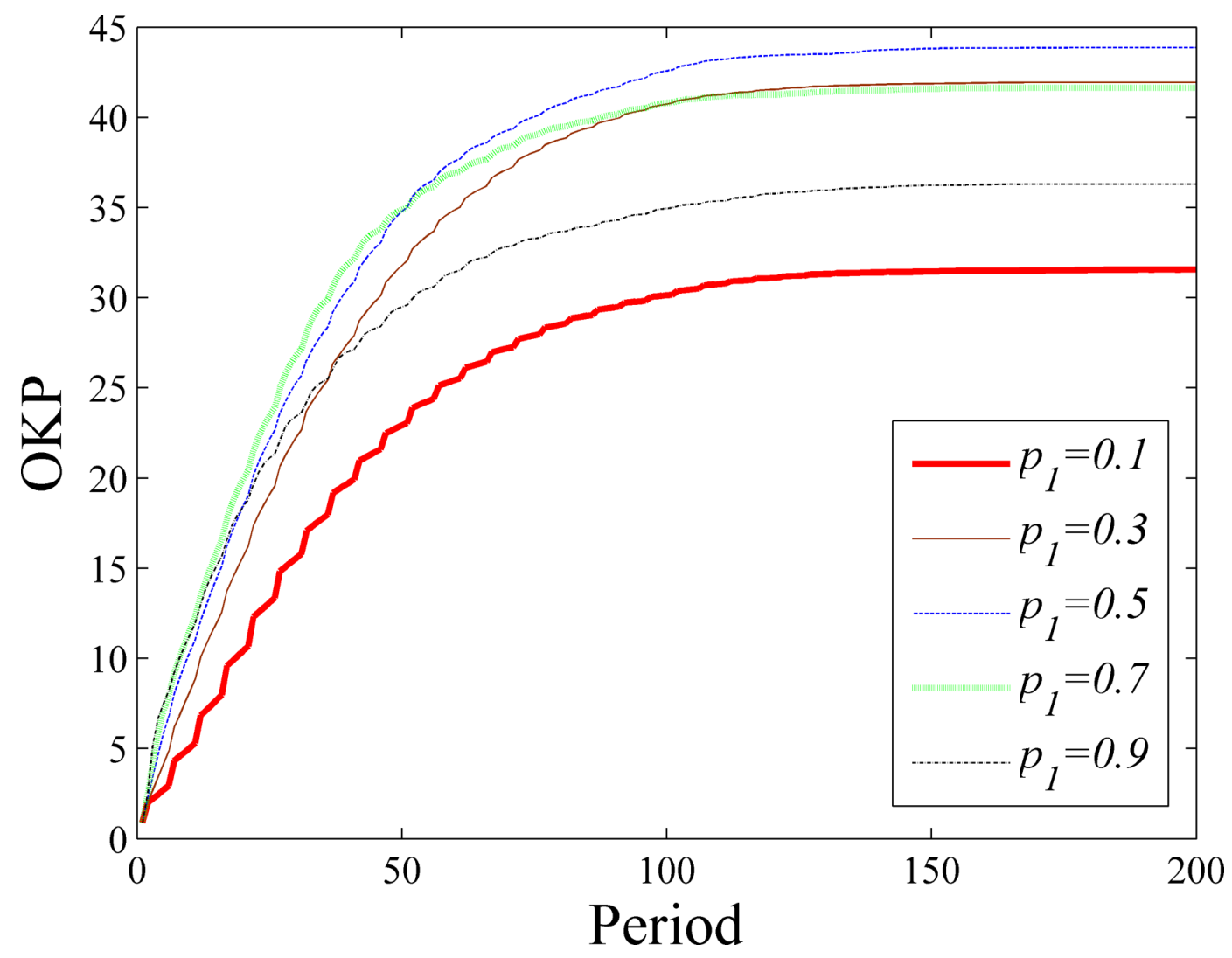

Similarly, within a team, a moderate rate of learning between the leader and members results in higher OWCOKP. The leader is a master of advanced knowledge in a team and plays a key role in spreading knowledge. Strengthening the learning between the leader and members is good for the diffusion of knowledge, which can improve OWCOKP. However, when the rate of the learning between the leader and members is too high, members will heavily rely on the leader to learn knowledge. This can also make team knowledge homogeneous and drive out team knowledge diversity, which negatively affects OWCOKP.

Figure 8 demonstrates the effect of the learning between different teams' members on OWCOKP. Figure 9 shows the effect of learning between different teams' leaders on OWCOKP.

As shown in Figure 8, when $p_{4}$ increases from 0.1 to 0.3 , the equilibrium OWCOKP also increases gradually. However, the equilibrium OWCOKP decreases gradually when $p_{4}$ increases from 0.3 to 0.9 . Moreover, as $p_{4}$ increases, the period of equilibrium OWCOKP decreases gradually. These results suggest that strengthening the learning between different teams' members is good for improving OWCOKP. However, it is not a high value of $p_{4}$ but a moderate value of $p_{4}$ that can produce higher OWCOKP. Our interpretation is as follows. Low learning rates between different teams' members prevent knowledge from being shared and utilized in time among different teams. This negatively affects the diffusion of knowledge among different teams. In contrast, with high learning rates, knowledge spreads and converges quickly among different teams, which decreases 
Figure 6. Effects of the team leader's learning from members on OKP within a team (Other parameters setting: $p_{1}=0.5, p_{3}$ $\left.=0.5, p_{4}=0.5, p_{5}=0.5\right)$

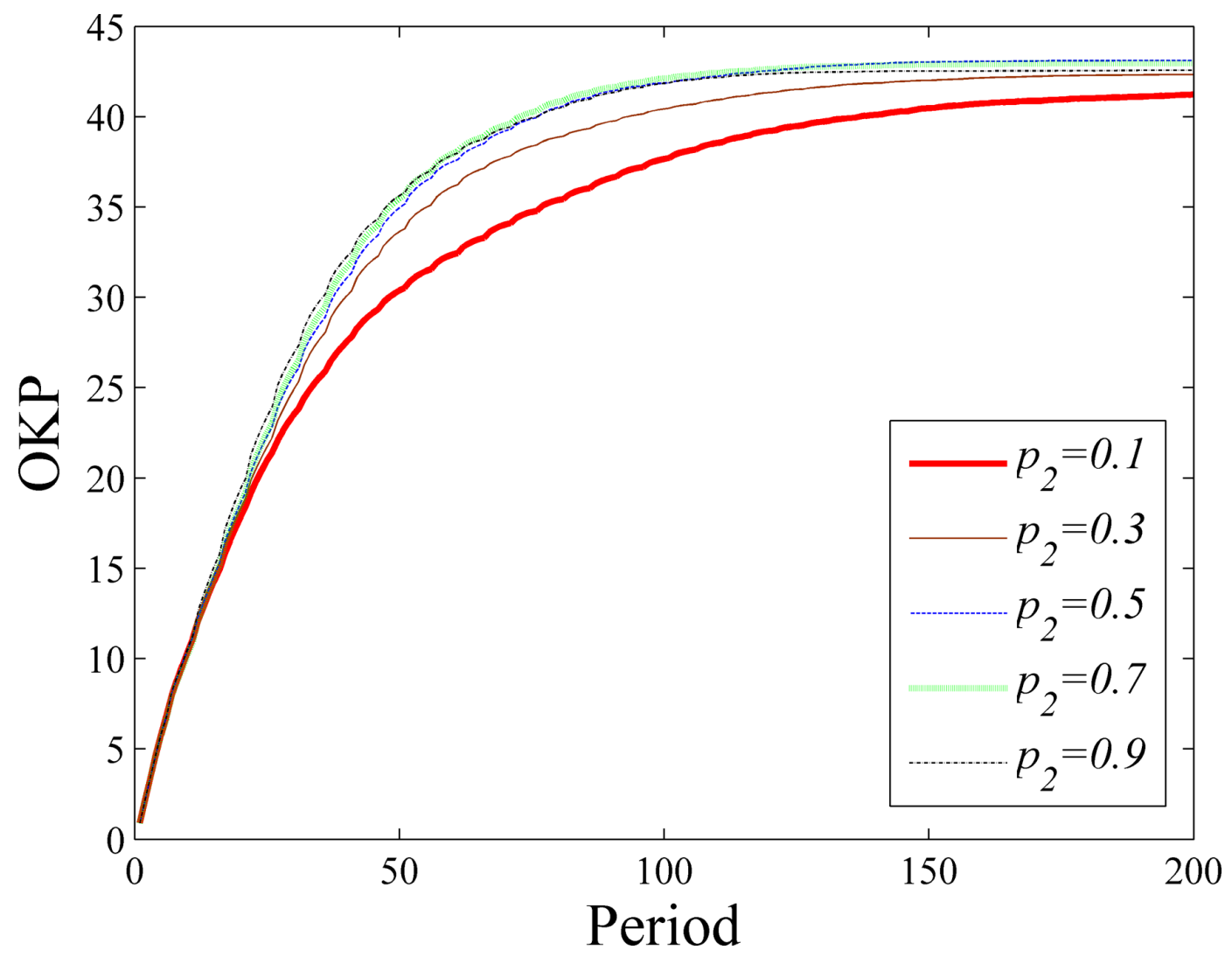

team knowledge diversity. With moderate learning rates, team knowledge diversity can be maintained longer. Moreover, knowledge can be effectively diffused among different teams with moderate learning rates. Therefore, moderate learning rates can lead to higher OWCOKP.

Figure 9 shows that as the rate of team leaders' learning from one another increases, equilibrium OWCOKP decreases gradually. Whereas rapid learning rates achieve equilibrium quickly in the short run, slow learning rates do so in the long run. A team leader who is the synthesizer of knowledge within a team is a key hub for connecting the team and other teams. Team leaders can learn advanced knowledge from other team leaders and then share the advanced knowledge with their own teams. Subsequently, team members can learn knowledge from their leader. When the rate of team leaders' learning from one another is high, leaders can learn advanced knowledge from one another quickly. This can improve OWCOKP in a short time. However, learning too fast can make the team absorb the knowledge of other teams passively, which is not conducive to the exploration and discovery of new knowledge within a team. This leads to lower OWCOKP in equilibrium. Slow learning between different team leaders encourages teams to explore new knowledge on their own, which helps maintain team knowledge diversity. Although this improves OWCOKP slowly, it can result in higher OWCOKP in equilibrium. 
Figure 7. Effects of team members' learning from the team leader on OKP within a team (Other parameters setting: $p_{1}=0.5, p_{2}$ $\left.=0.5, p_{4}=0.5, p_{5}=0.5\right)$

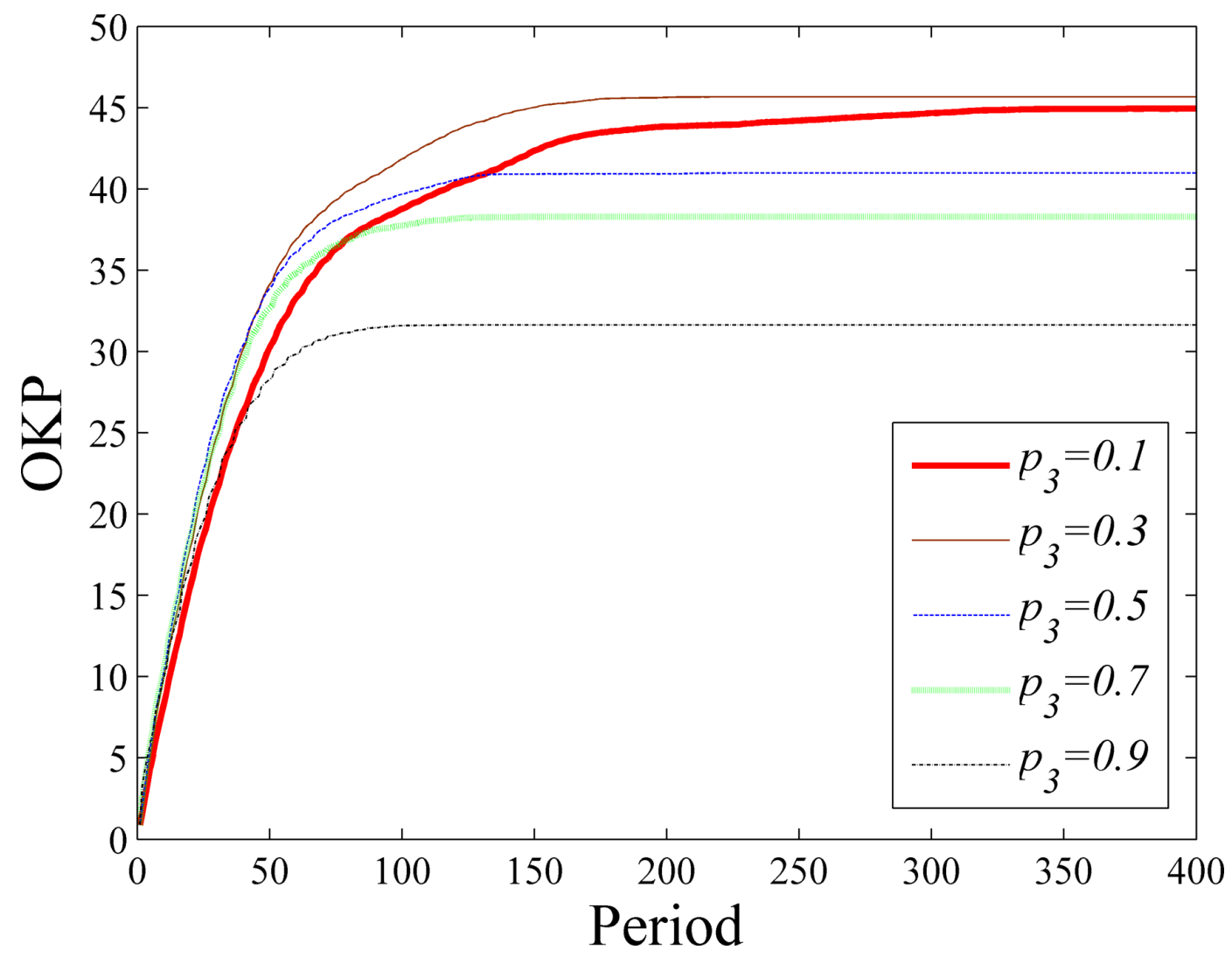

\section{With Leaders' Forgetting}

Second, we investigate the effect of the double-layer learning structure on OWCOKP with leaders' forgetting. As mentioned above, given the important role of leaders in an organization, we mainly focus on how leaders' forgetting influences OWCOKP. Therefore, in this section, we assume that leaders convert a nonzero belief ( 1 or -1 ) of his knowledge vector into a zero belief (0) with probability $f$ in each period. The simulation results and analysis are as follows.

Figure 10 shows the effect of the degree of different teams' member connectivity on OWCOKP with leaders' forgetting. The results in Figure 10 are also obtained by simulating the model until it achieves long-run equilibrium OWCOKP. As shown in Figure 10, with leaders' forgetting $(f=0.05$ and $f=0.1$, there is also an inverted-U relationship between the degree of different teams' member connectivity and OWCOKP. Furthermore, as leaders' forgetting rate increases, first, OWCOKP decreases as a whole. Second, the values of $r$, which lead to optimal OWCOKP, rise.

Similarly, with leaders' forgetting, moderate connections between different teams' members not only maintain team knowledge diversity longer but also help diffuse diverse knowledge among teams, which can improve OWCOKP. Forgetting converts a nonzero belief of the leader knowledge vector to a zero belief, which tends to drive leaders to hold zero beliefs (Miller \& Martignoni, 2016). Moreover, by learning from the leader, members within a team also tend to be driven to hold zero beliefs. This results in the loss of team knowledge diversity. Increasing connections moderately between different teams' members can strengthen the mutual learning between different teams. 
Figure 8. Effects of different team members' learning from one another on OKP (Other parameters setting: $p_{1}=0.5, p_{2}=0.5$, $\left.p_{3}=0.5, p_{5}=0.5\right)$

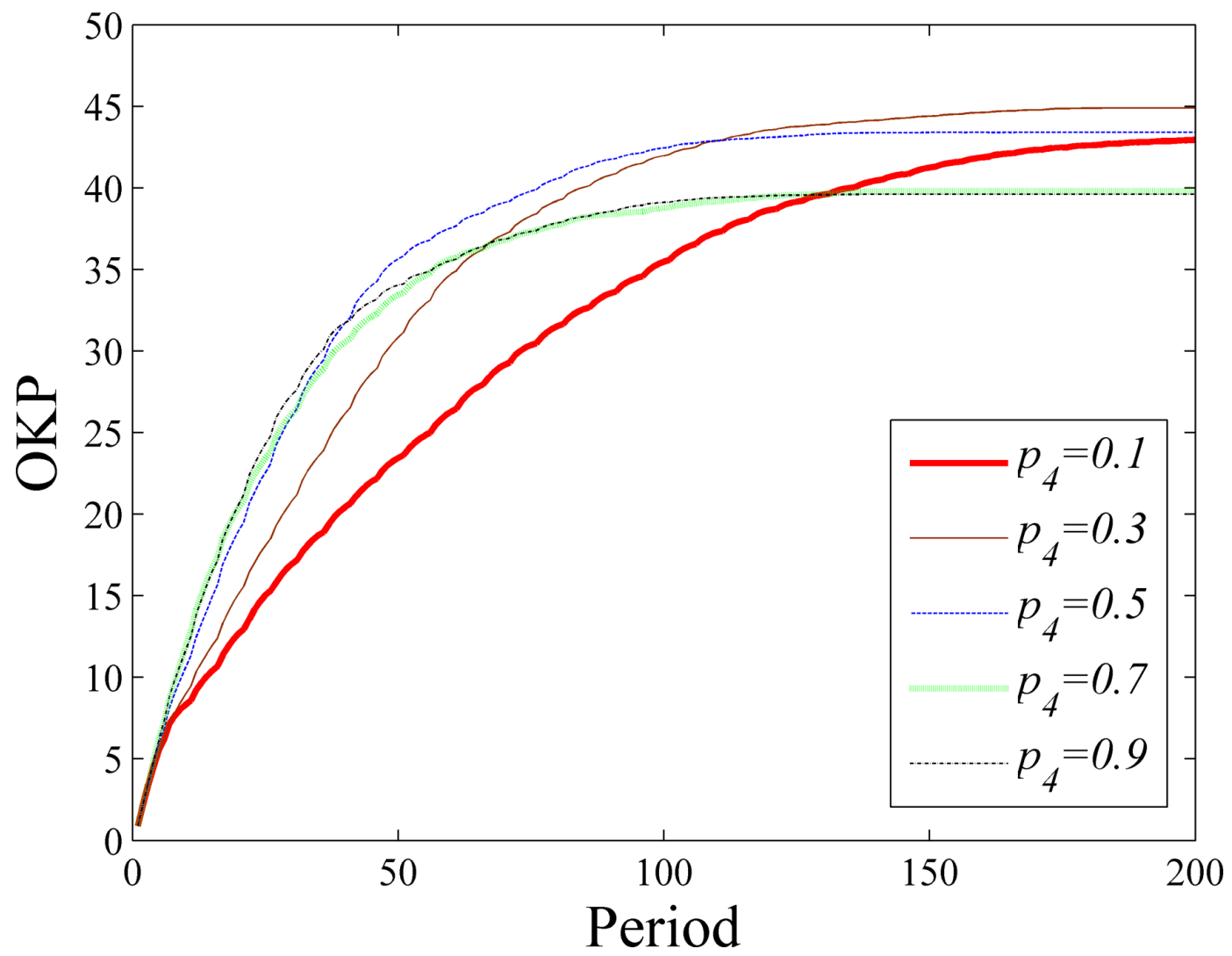

More connections between different teams' members facilitate the effective sharing and exchange of advanced knowledge among teams. Therefore, increasing connections can improve team knowledge diversity, which leads to higher OWCOKP.

Next, we study the effect of the rate of leaders' and members' learning on OWCOKP with leaders' forgetting. To compare the results with leaders' forgetting and those without leaders' forgetting, we fix the network connection between different teams' members. That is, we set the value of $r$ as 0.1 and the rate of leaders' forgetting as $0.1(f=0.1)$. The simulation results and analysis are as follows.

The results shown in Figure 11 to Figure 15 show the effect of the rate of leaders' and members' learning on OWCOKP with leaders' forgetting. In comparing the results, we find that OWCOKP in equilibrium with leaders' forgetting is lower than that without leaders' forgetting. In addition, leaders' forgetting has a significant effect on the relationship between the learning between different teams' leaders and OWCOKP. However, leaders' forgetting has little influence on the other four learning processes.

Specifically, there is a negative correlation between the learning rate between different teams' leaders and OWCOKP without leaders' forgetting. However, with leaders' forgetting, there is an inverted-U relationship between them. As mentioned above, forgetting tends to drive leaders and members to hold zero beliefs, which results in the loss of team knowledge diversity. At this point, leaders strengthen knowledge learning from one another, which can help change the trend of driving leaders and members to hold zero beliefs. On the one hand, converting a nonzero belief of the leader 
Figure 9. Effects of different team leaders' learning from one another on OKP (Other parameters setting: $p_{1}=0.5, p_{2}=0.5, p_{3}$ $\left.=0.5, p_{4}=0.5\right)$

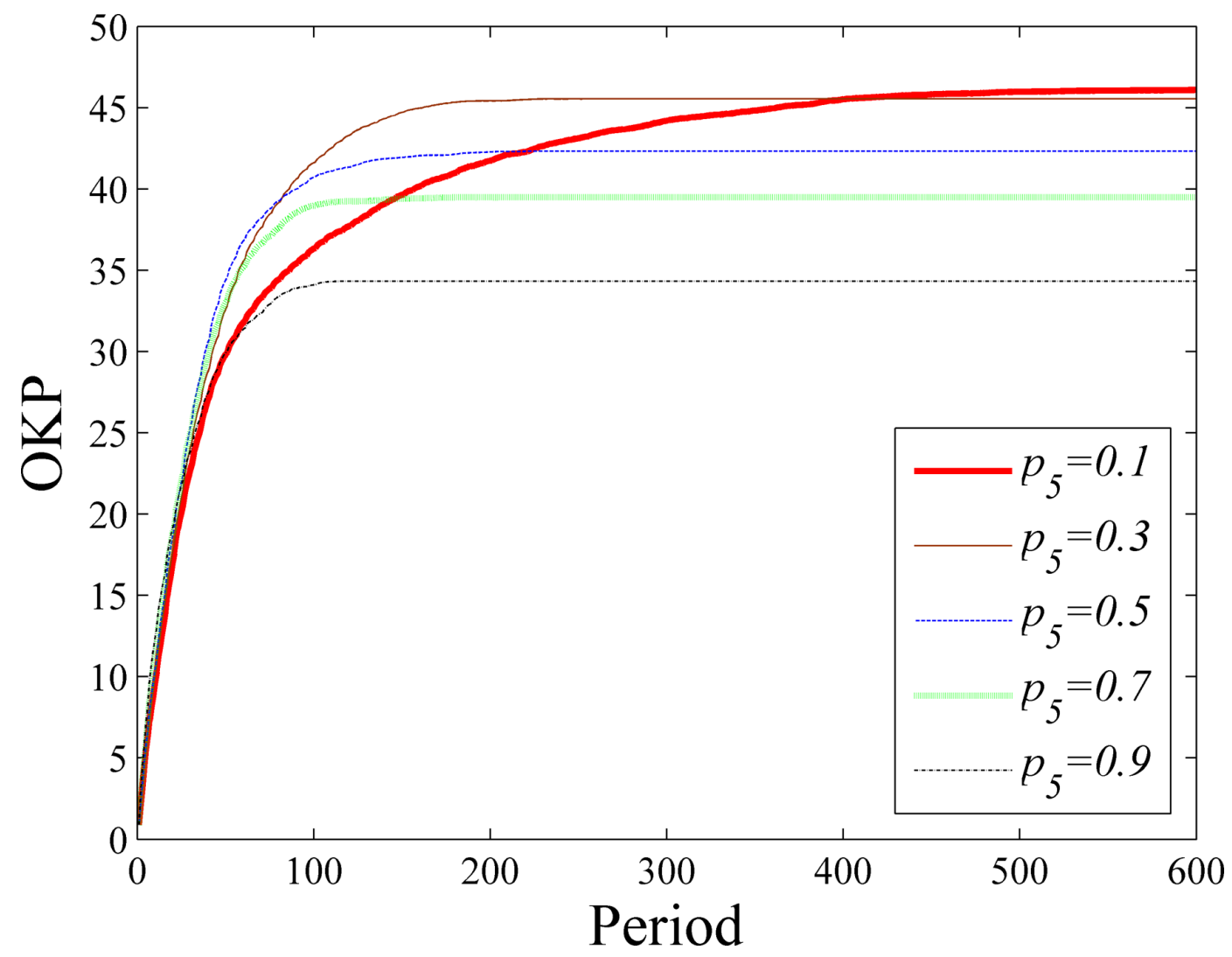

knowledge vector to a zero belief creates the conditions for the leader to learn new knowledge. On the other hand, strengthening knowledge learning between different teams' leaders can help leaders learn new knowledge from one another. Thus, team knowledge diversity can be preserved, which has a positive effect on OWCOKP. However, when the learning rate between different teams' leaders is too fast, team knowledge will quickly become homogeneous. Knowledge homogeneity drives out team knowledge diversity, which has a negative effect on OWCOKP.

\section{CONCLUSION}

Focusing on the problem of how multi-layer structures and multi-level learning between individuals in an online work community organization influence OWCOKP, this paper constructs an online work community organizational double-layer learning structure model using computer simulation methods. In addition, we emphasize the role of leaders and mainly examine how leaders' forgetting in multi-layer structures affects OWCOKP. In this way, we investigate the effect of double-layer learning on OWCOKP in two situations: with leaders' forgetting and without leaders' forgetting. The results first suggest that with or without leaders' forgetting, there is an inverted-U relationship between the degree of different teams' member connectivity and OWCOKP. Second, as the leaders' forgetting rate increases, the degree of different teams' member connectivity, which leads to the optimum OWCOKP, also increases. Third, with or without leaders' forgetting, moderate learning 
Figure 10. Effects of the degree of different teams' member connectivity on OKP with leaders' forgetting (Other parameters setting: $\left.p_{1}=0.5, p_{2}=0.5, p_{3}=0.5, p_{4}=0.5, p_{5}=0.5\right)$

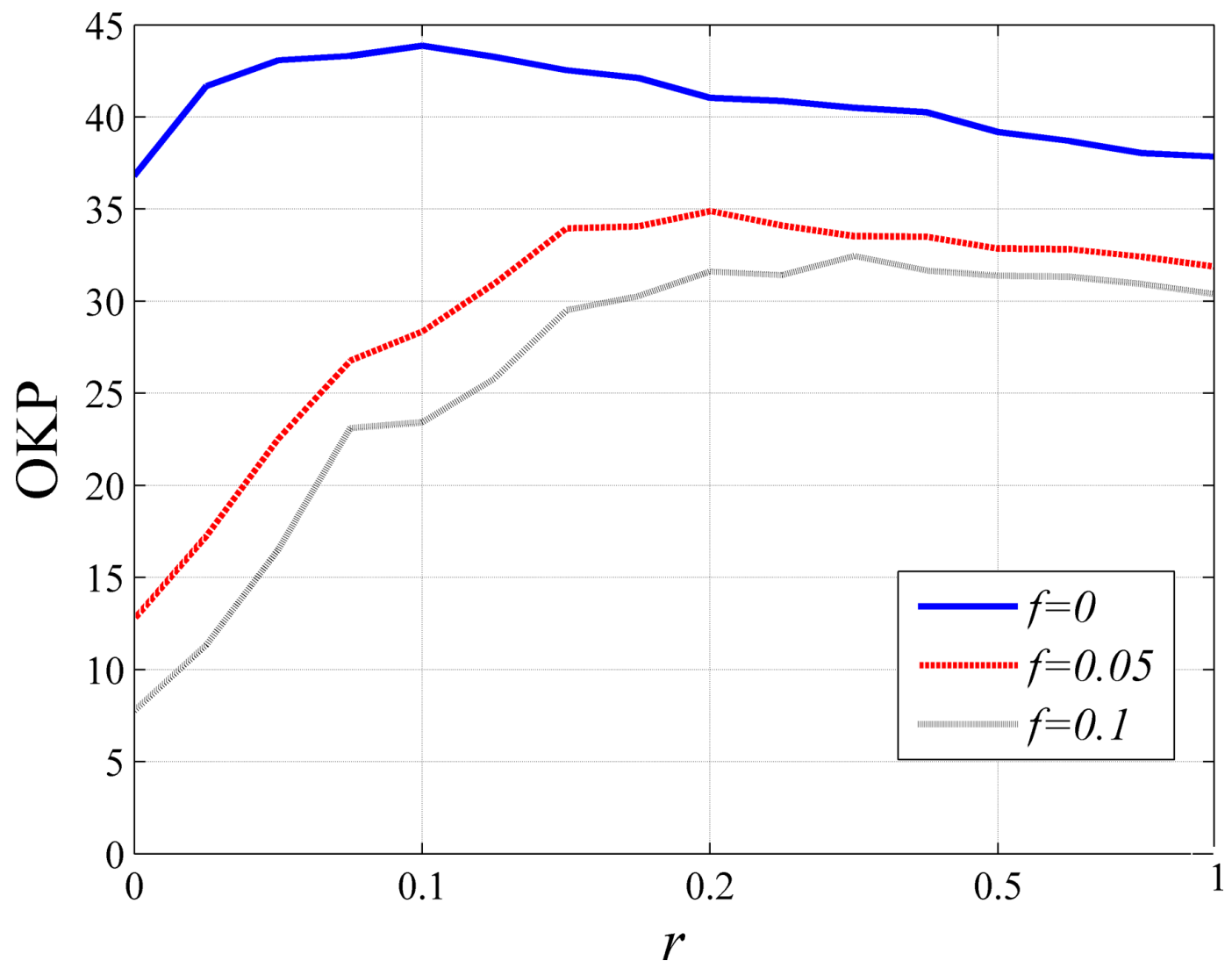

between members and that between the leader and members can improve OWCOKP within a team. Between different teams' members, the condition for improving OWCOKP is also moderate learning. Fourth, in different teams, slow learning between leaders produces higher OWCOKP without leaders' forgetting, while moderate learning between leaders produces higher OWCOKP with their forgetting.

Our study contributes to the literature on online work community organizational learning in two main ways. First, by constructing an organizational double-layer learning structure model, we study multi-level learning within teams and across different teams. Second, we add leaders' forgetting to our double-layer learning structure model, and we compare the multi-level learning process within an online work community organization in two situations: with leaders' forgetting and without leaders' forgetting.

The first contribution of our study is that we extend the prior exploration-exploitation models on online work community organizational learning (e.g., C. Fang et al., 2010; March, 1991; Miller et al., 2006) by constructing an organizational double-layer learning structure model. In the prior exploration-exploitation models, researchers investigated a single-layer structure between individuals and regarded individuals as a homogeneous group within the organization. In our model, individuals within an online work community organization are divided into two layers: leaders and members. In addition, the network structure of individuals within a team and that between different teams are both considered in our model. Based on the organizational double-layer learning structure model, we fully study the multi-level learning process in an online work community organization. The learning 
Figure 11. Effects of members' learning from one another on OKP within a team with leaders' forgetting (Other parameters setting: $\left.p_{2}=0.5, p_{3}=0.5, p_{4}=0.5, p_{5}=0.5\right)$

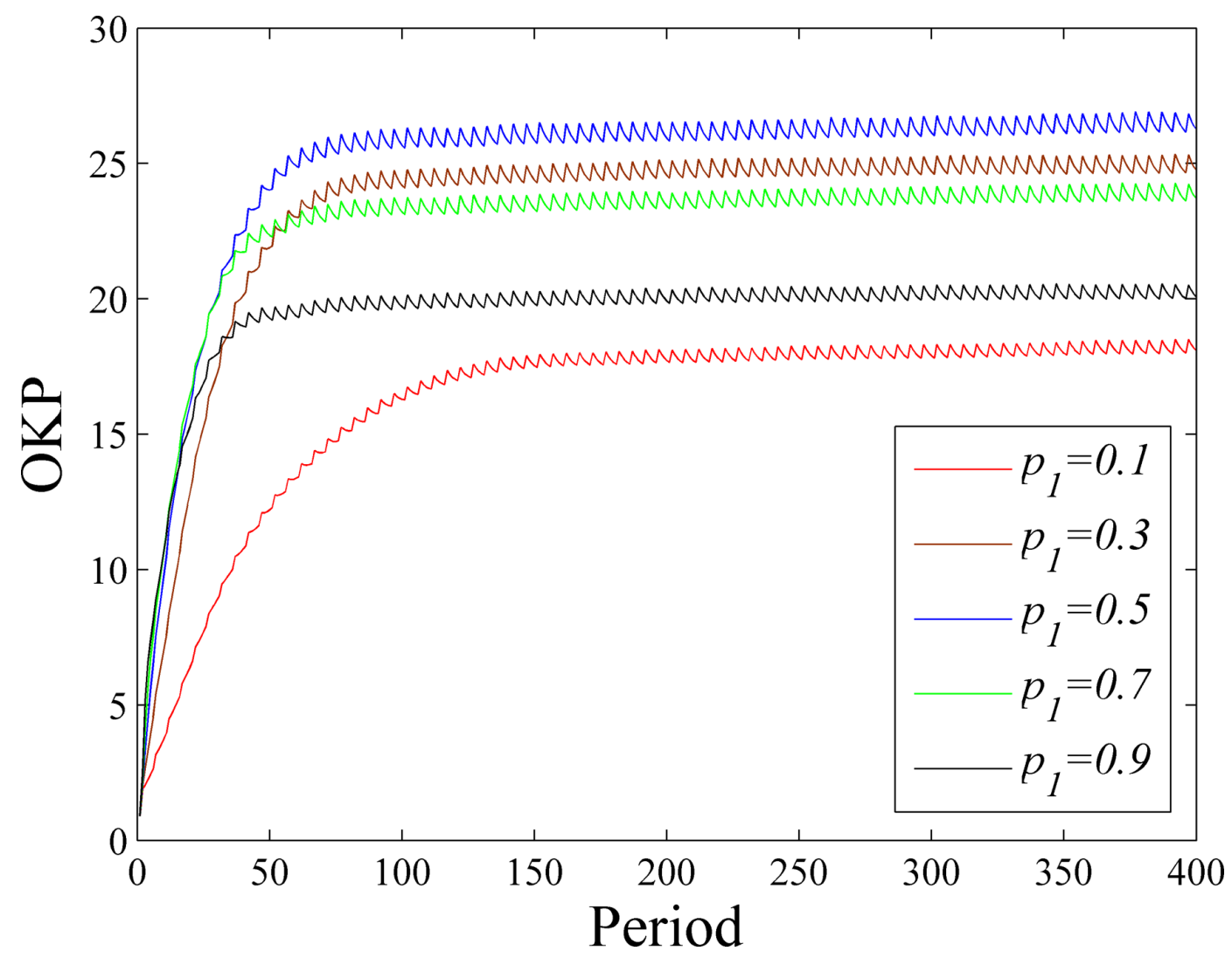

process includes learning within a team and learning between different teams. The former includes learning between members and learning between the leader and members within a team. The latter includes learning between different teams' members and learning between different teams' leaders. In this way, we can investigate how multi-layer structures and multi-level learning between individuals in an organization influence OWCOKP.

Second, our study contributes to the literature on online work community organizational learning by adding leaders' forgetting. Our study compares the learning processes with leaders' forgetting and without leaders' forgetting. In previous studies, several exploration-exploitation models of organizational learning consider forgetting. Previous studies (e.g., Blaschke \& Schoeneborn, 2006; Miller \& Martignoni, 2016) have suggested that similar to organizational learning, forgetting has an important effect on OWCOKP. Knowledge in online work community organizations may be out of date, and innovative activities often have a significant impact on the current stock of organizational knowledge (Greve \& Taylor, 2000). With a constantly changing external environment, some original knowledge of online work community organizations has been unable to adapt to the environmental changes (Martinez-Plumed et al., 2015). Forgetting useless knowledge can create conditions for new knowledge. In addition, the role of leaders, who guide organizations, identify environmental needs, and facilitate appropriate developments, is very important for online work community organizations. We emphasize the role of leaders and mainly examine how leaders' forgetting in multi-layer structures affects OWCOKP. Therefore, in our paper, both learning and forgetting are considered as we compare two situations: with leaders' forgetting and without leaders' forgetting. 
Figure 12. Effects of the team leader's learning from members on OKP within a team with leaders' forgetting (Other parameters setting: $\left.p_{1}=0.5, p_{3}=0.5, p_{4}=0.5, p_{5}=0.5\right)$

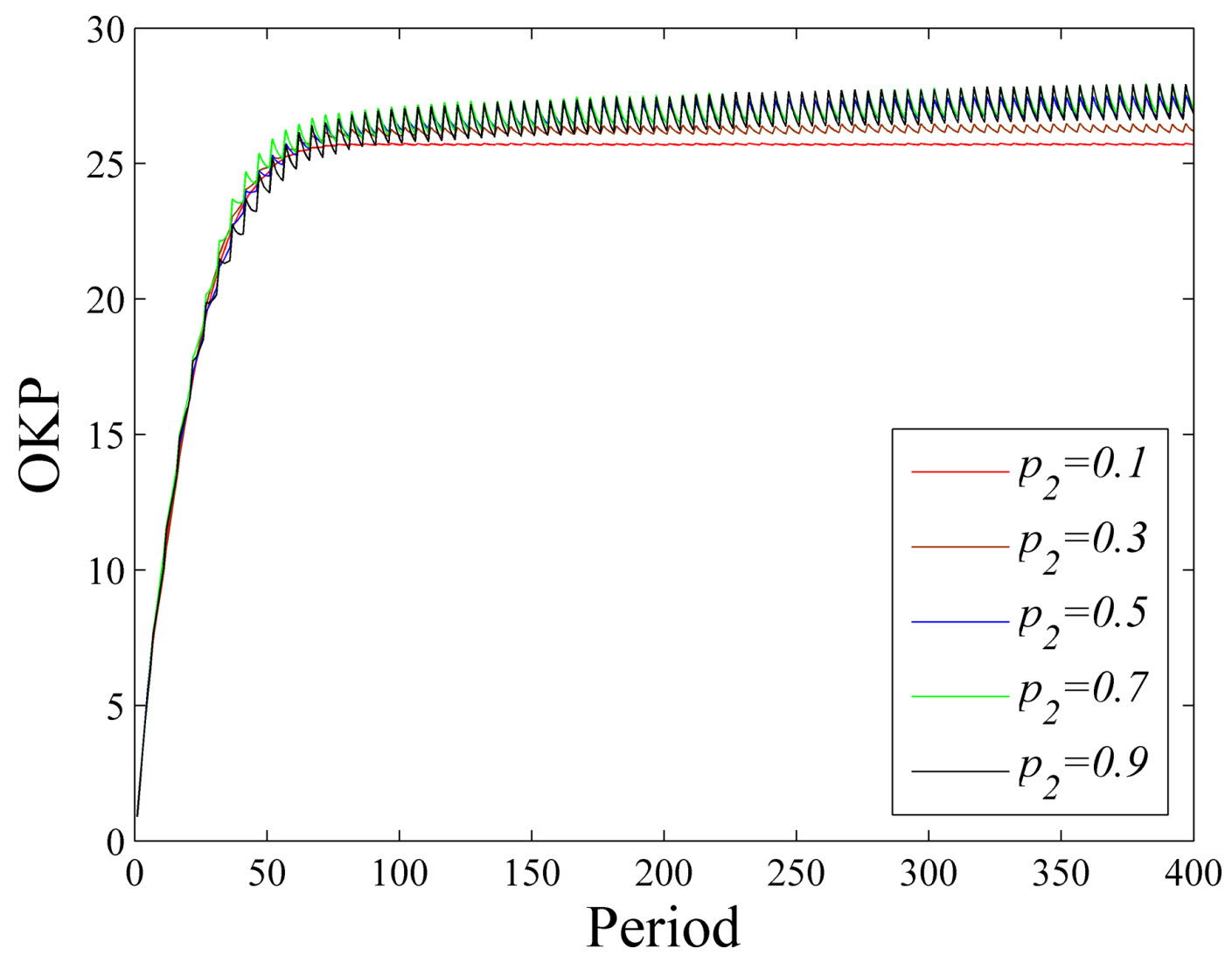

\section{Theoretical Implications}

Our study has several theoretical implications for online work community organizational learning. In the field of organizational learning, scholars have performed much research on exploration and exploitation (e.g., Chae et al., 2015; Liao et al., 2011) and how to balance exploration and exploitation through the organizational structure (e.g., C. Fang et al., 2010; Jansen et al., 2006). However, most previous studies have focused on the single-layer structure between individuals in organizations, that is, they have regarded individuals as equals. There is little focus on the multi-layer structure or multi-level learning between individuals (such as leaders and members) in an organization. This paper constructs an online work community organizational double-layer learning structure model through computer simulation methods. In our model, we divide individuals of an online work community organization into two layers: leaders and members. This model helps us study the learning process between leaders and members in an online work community organization more comprehensively. Forgetting has also been considered in this study. We compare the effect of a double-layer learning structure on OWCOKP with leaders' forgetting and that without leaders' forgetting. This study supplements the theory of online work community organizational learning to some extent and provides theoretical references for future research. 
Figure 13. Effects of team members' learning from the team leader on OKP within a team with leaders' forgetting (Other parameters setting: $p_{1}=0.5, p_{2}=0.5, p_{4}=0.5, p_{5}=0.5$ )

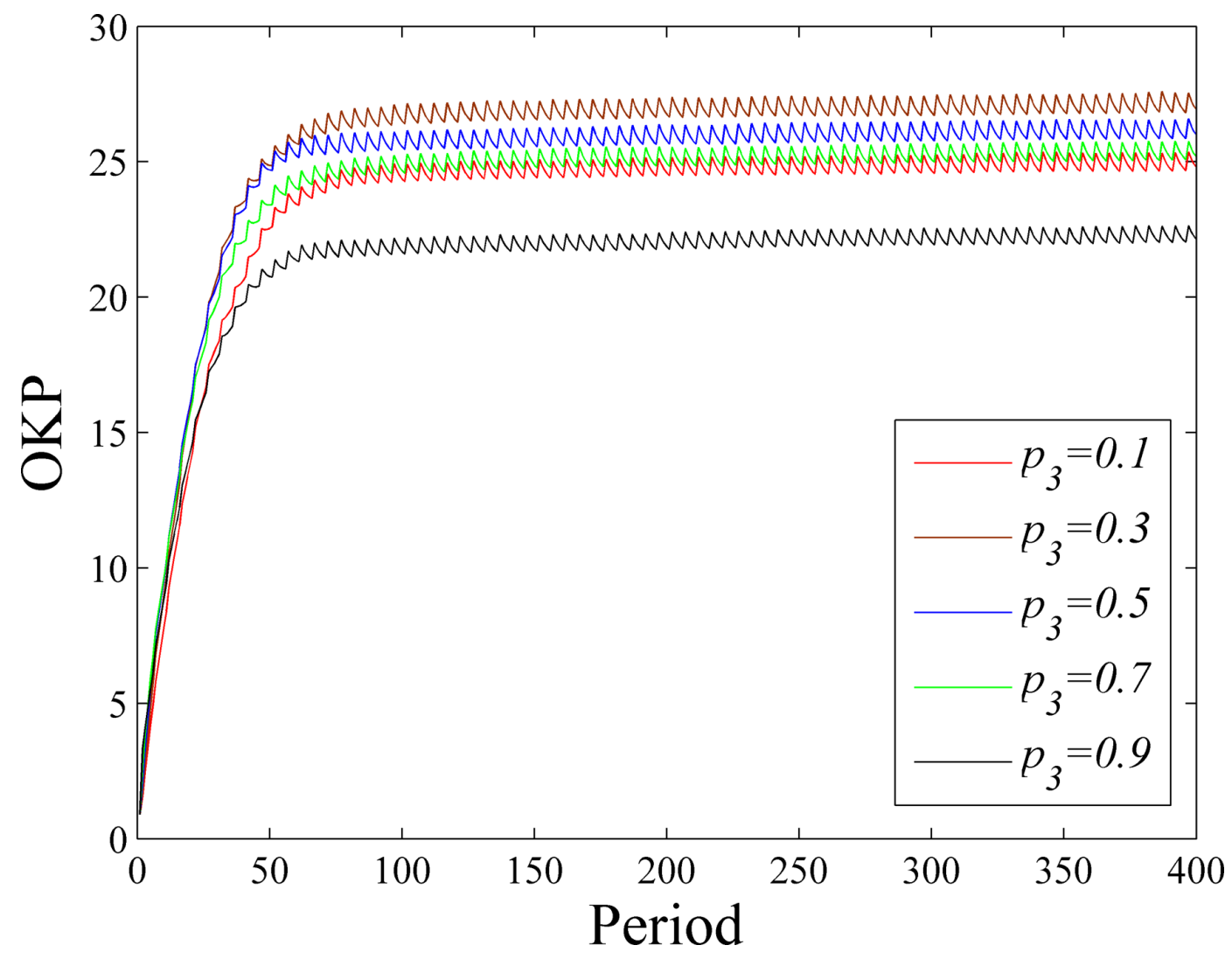

\section{Practical Implications}

Our study also has some practical implications for online work community organizational managers. First, within teams in an online work community organization, team leaders should strengthen their contact with team members in daily work (Berson, Da' as, \& Waldman, 2015). On the one hand, through mutual learning between team leaders and members, leaders can integrate the advanced knowledge of members. On the other hand, leaders can diffuse the advanced knowledge within the team in a timely manner. Leaders should manage their own behaviour (e.g., leadership style) in different stages of the learning processes (Sun \& Anderson, 2012). It must be noted that leaders should also moderately control the mutual learning between members (Owens \& Hekman, 2012) and encourage members to explore new knowledge by themselves. This can help maintain team knowledge diversity and help improve OWCOKP. For example, team leaders should encourage members to combine drawing lessons from experiences with thinking independently to solve problems. Similarly, team members should moderately learn from one another. In this way, team members may not only explore new knowledge by themselves but also learn advanced knowledge from other members. Therefore, team leaders should create a good learning climate (Berson et al., 2015) and establish a reasonable exchange mechanism for team members.

Second, between different teams in an online work community organization, different teams' members should moderately set up connections with one another to exchange knowledge. Previous research argues that semi-isolated groups in an organization might encourage them to explore 
Figure 14. Effects of different team members' learning from one another on OKP with leaders' forgetting (Other parameters setting: $\left.p_{1}=0.5, p_{2}=0.5, p_{3}=0.5, p_{5}=0.5\right)$

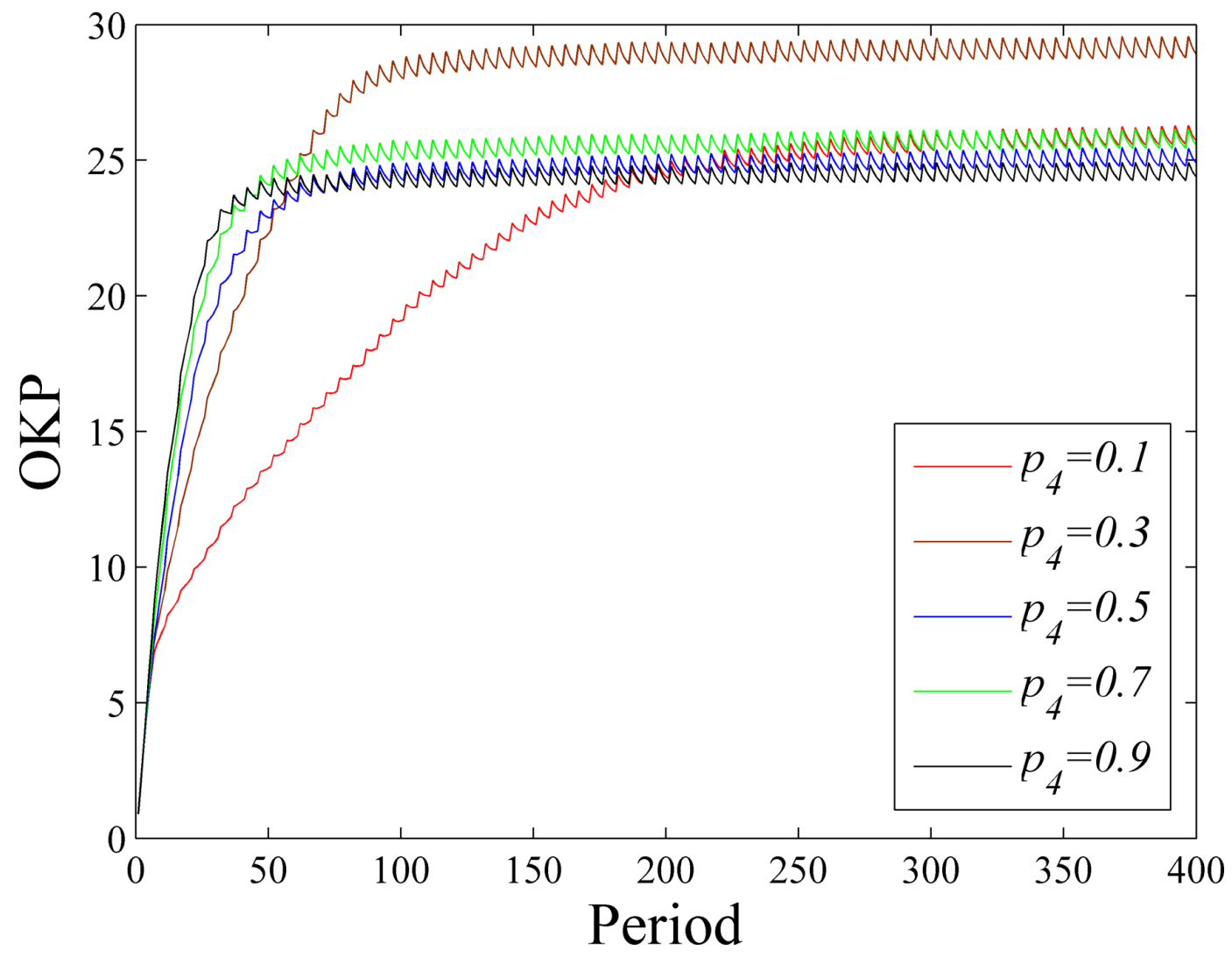

diverse solutions, while moderate connections between different groups enable superior solutions to eventually be exploited throughout the organization (e.g., C. Fang et al., 2010; Schilling \& Fang, 2014). That is, on the one hand, a team in an online work community organization cannot develop itself in isolation. On the other hand, a team cannot rely too heavily on learning from other teams to improve itself. Therefore, teams should focus on the exploration and innovation of knowledge within a team while learning advanced knowledge from other teams. Doing so is conducive to the long-term development of teams.

Finally, as organizations focus on organizational learning, they should not neglect forgetting. Competitiveness is not just about learning; it is also about forgetting the outdated things at the right times (Derbinsky \& Laird, 2013). For example, if the existing knowledge is extraneous or is actively interfering with the application of more appropriate knowledge, forgetting is a positive occurrence (Holan \& Phillips, 2013). Therefore, on the one hand, teams in online work community organizations must be aware of the negative effects of outdated knowledge and should continue to test the validity of existing knowledge and practice (Huang et al., 2018). They should pay attention to appropriately discarding useless old knowledge when learning new knowledge. They can create conditions for the better creation and absorption of new knowledge by doing so. On the other hand, with forgetting, teams should moderately strengthen knowledge learning between them. In this way, team knowledge diversity can be maintained longer in the joint action of learning and forgetting. This can make organizations more able to adapt to the environment. 
Figure 15. Effects of different team leaders' learning from one another on OKP with leaders' forgetting (Other parameters setting: $\left.p_{1}=0.5, p_{2}=0.5, p_{3}=0.5, p_{4}=0.5\right)$

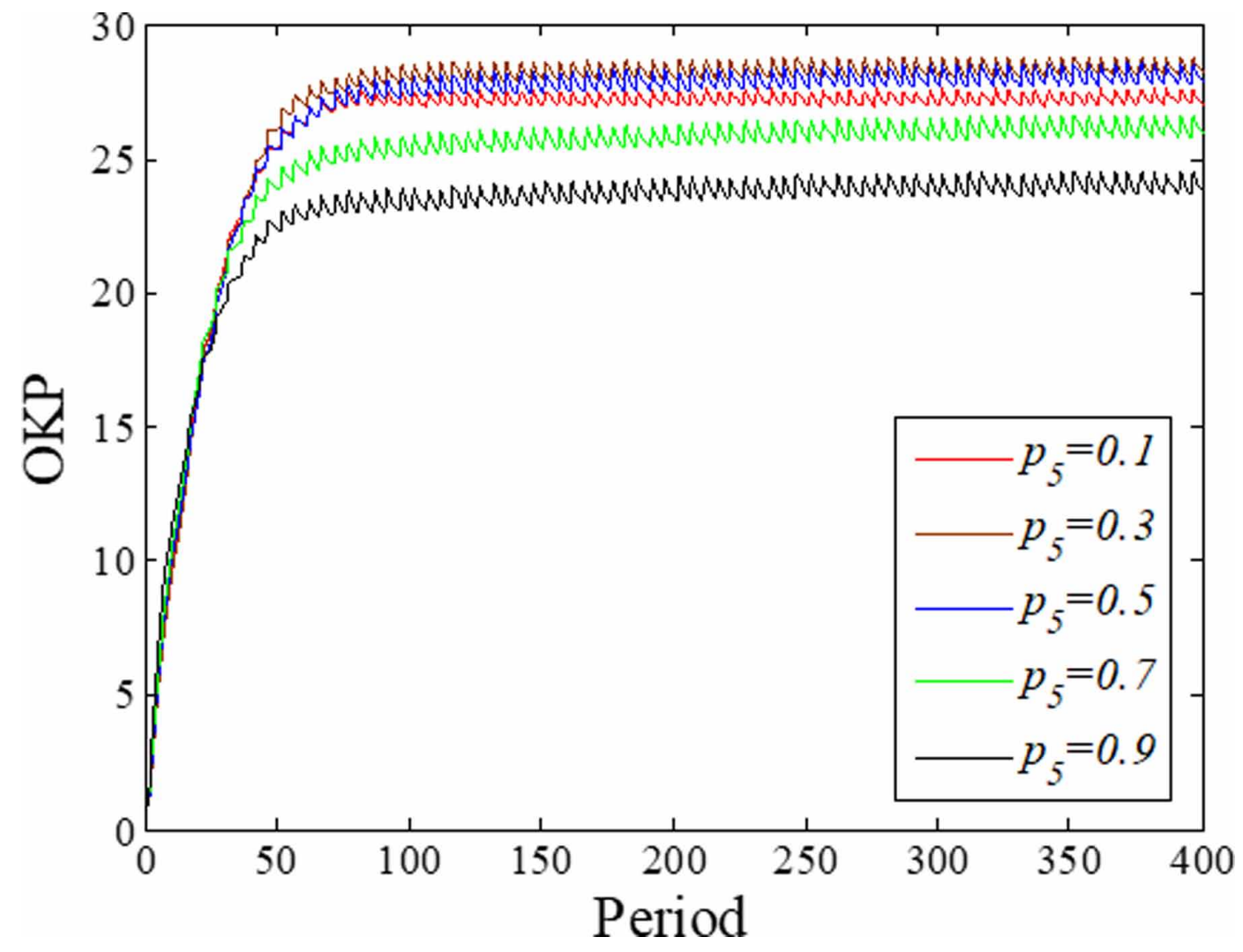

\section{LIMITATIONS AND FUTURE DIRECTION}

Our paper used a computer simulation model to investigate the effect of double-layer learning on OWCOKP in two situations: with leaders' forgetting and without leaders' forgetting. However, of course, much more research and empirical work are required. In our model, each leader is connected to other teams' leaders. This is a typical network structure but not the only network structure between different teams' leaders within an online work community organization. Future research may discuss the effect of different network structures between different teams' leaders on OWCOKP. In addition, the simulation in our paper is based on prior empirical research but it is not an empirical analysis. Further empirical work is needed to confirm our results and to develop a deeper understanding of the explanation of our results. 


\section{REFERENCES}

Adler, P. S., \& Kwon, S. W. (2002). Social capital: Prospects for a new concept. Academy of Management Review, 27(1), 17-40. doi:10.5465/amr.2002.5922314

Argote, L., \& Ingram, P. (2000). Knowledge transfer: A basis for competitive advantage in firms. Organizational Behavior and Human Decision Processes, 82(1), 150-169. doi:10.1006/obhd.2000.2893

Argote, L., \& Miron-Spektor, E. (2011). Organizational learning: From experience to knowledge. Organization Science, 22(5), 1123-1137. doi:10.1287/orsc.1100.0621

Aydin, E., \& Gormus, A. S. (2015). Does organizational forgetting matter? Organizational survival for life coaching companies. The Learning Organization, 22(3), 150-162. doi:10.1108/TLO-12-2014-0068

Berends, H., \& Antonacopoulou, E. (2014). Time and organizational learning: A review and agenda for future research. International Journal of Management Reviews, 16(4), 437-453. doi:10.1111/ijmr.12029

Berson, Y., Da'as, R., \& Waldman, D. A. (2015). How Do Leaders and Their Teams Bring About Organizational Learning and Outcomes? Personnel Psychology, 68(1), 79-108. doi:10.1111/peps.12071

Blaschke, S., \& Schoeneborn, D. (2006). The Forgotten Function of Forgetting: Revisiting Exploration and Exploitation in Organizational Learning. Soziale Systeme, 12(1), 100-120. doi:10.1515/sosys-2006-0107

Brunsson, K. (1998). Non-Learning Organizations. Scandinavian Journal of Management, 14(4), 421-432. doi:10.1016/S0956-5221(98)00002-5

Bunderson, J. S., \& Boumgarden, P. (2010). Structure and Learning in Self-Managed Teams: Why "Bureaucratic" Teams Can Be Better Learners. Organization Science, 21(3), 609-624. doi:10.1287/orsc.1090.0483

Carley, K. (1992). Organizational Learning and Personnel Turnover. Organization Science, 3(1), 20-46. doi:10.1287/orsc.3.1.20

Chae, S. W., Seo, Y. W., \& Lee, K. C. (2015). Task difficulty and team diversity on team creativity: Multi-agent simulation approach. Computers in Human Behavior, 42, 83-92. doi:10.1016/j.chb.2014.03.032

Chanda, S. S., \& Ray, S. (2015). Optimal exploration and exploitation: The managerial intentionality perspective. Computational \& Mathematical Organization Theory, 21(3), 247-273. doi:10.1007/s10588-015-9184-y

Chang, H. H., Wong, K. H., Eng, C. J., \& Chen, S.-H. (2018). Consumption value and social capital on sense of virtual community toward value of co-created information. Journal of Organizational and End User Computing, 30(1), 44-65. doi:10.4018/JOEUC.2018010103

Choi, K., Park, N. K., \& Lee, J. (2015). The hierarchy myopia of organizational learning. Seoul Journal of Business, 21(2), 71-104. doi:10.35152/snusjb.2015.21.2.003

Cohen, W. M., \& Levinthal, D. A. (1990). Absorptive capacity: A new perspective on learning and innovation. Administrative Science Quarterly, 35(1), 128-152. doi:10.2307/2393553

Daft, R. L., \& Weick, K. E. (1984). Toward a Model of Organizations as Interpretation Systems. Academy of Management Review, 9(2), 284-295. doi:10.5465/amr.1984.4277657

Dahlander, L., \& Frederiksen, L. (2012). The core and cosmopolitans: A relational view of innovation in user communities. Organization Science, 23(4), 988-1007. doi:10.1287/orsc.1110.0673

Derbinsky, N., \& Laird, J. E. (2013). Effective and efficient forgetting of learned knowledge in Soar's working and procedural memories. Cognitive Systems Research, 24, 104-113. doi:10.1016/j.cogsys.2012.12.003

Fang, C., Lee, J., \& Schilling, M. A. (2010). Balancing Exploration and Exploitation Through Structural Design: The Isolation of Subgroups and Organizational Learning. Organization Science, 21(3), 625-642. doi:10.1287/ orsc. 1090.0468

Fang, J., Chen, L., Wang, X., \& George, B. (2018). Not all posts are treated equal: An empirical investigation of post replying behavior in an online travel community. Information \& Management, 55(7), 890-900. doi:10.1016/j. im.2018.04.003 
Fernandez, V., \& Sune, A. (2009). Organizational forgetting and its causes: An empirical research. Journal of Organizational Change Management, 22(6), 620-634. doi:10.1108/09534810910997032

Greve, H. R., \& Taylor, A. (2000). Innovations as Catalysts for Organizational Change: Shifts in Organizational Cognition and Search. Administrative Science Quarterly, 45(1), 54-80. doi:10.2307/2666979

Guechtouli, W., Rouchier, J., \& Orillard, M. (2013). Structuring knowledge transfer from experts to newcomers. Journal of Knowledge Management, 17(1), 47-68. doi:10.1108/13673271311300741

Gupta, A. K., Tesluk, P. E., \& Taylor, M. S. (2007). Innovation at and across multiple levels of analysis. Organization Science, 18(6), 885-897. doi:10.1287/orsc.1070.0337

Hamidi, H., \& Jahanshahifard, M. (2018). The Role of the Internet of Things in the Improvement and Expansion of Business. Journal of Organizational and End User Computing, 30(3), 24-44. doi:10.4018/JOEUC.2018070102

Harrison, R. T., \& Leitch, C. M. (2005). Entrepreneurial learning: Researching the interface between learning and the entrepreneurial context. Entrepreneurship Theory and Practice, 29(4), 351-371. doi:10.1111/j.15406520.2005.00089.x

Hislop, D., Bosley, S., Coombs, C. R., \& Holland, J. (2014). The process of individual unlearning: A neglected topic in an under-researched field. Management Learning, 45(5), 540-560. doi:10.1177/1350507613486423

Holan, P. M. D., \& Phillips, N. (2004a). Organizational forgetting as strategy. Strategic Organization, 2(4), 423-433. doi:10.1177/1476127004047620

Holan, P. M. D., \& Phillips, N. (2004b). Remembrance of Things Past? The Dynamics of Organizational Forgetting. Management Science, 50(11), 1603-1613. doi:10.1287/mnsc.1040.0273

Holan, P. M. D., \& Phillips, N. (2013). Organizational Forgetting. In M. Easterby-Smith \& M. Lyles (Eds.), Handbook of Organizational Learning and Knowledge Management (pp. 433-452). John Wiley \& Sons, Inc.

Huang, D., Chen, S., Zhang, G., \& Ye, J. (2018). Organizational forgetting, absorptive capacity, and innovation performance: A moderated mediation analysis. Management Decision, 56(1), 87-104. doi:10.1108/MD-032017-0200

Hurley, R. F., \& Hult, G. T. M. (1998). Innovation, market orientation, and organizational learning: An integration and empirical examination. Journal of Marketing, 62(3), 42-54. doi:10.1177/002224299806200303

Jansen, J. J. P., Van den Bosch, F. A. J., \& Volberda, H. W. (2006). Exploratory innovation, exploitative innovation, and performance: Effects of organizational antecedents and environmental moderators. Management Science, 52(11), 1661-1674. doi:10.1287/mnsc.1060.0576

Jr, F. D., Graen, G., \& Haga, W. J. (1975). A vertical dyad linkage approach to leadership within formal organizations : A longitudinal investigation of the role making process. Organizational Behavior and Human Performance, 13(1), 46-78. doi:10.1016/0030-5073(75)90005-7

Kim, H. (2019). Investigating the Mediating Role of Social Networking Service Usage on the Big Five Personality Traits and on the Job Satisfaction of Korean Workers. Journal of Organizational and End User Computing, 31(1), 110-123. doi:10.4018/JOEUC.2019010106

Kim, T., \& Rhee, M. (2009). Exploration and exploitation: Internal variety and environmental dynamism. Strategic Organization, 7(1), 11-41. doi:10.1177/1476127008100125

Knudsen, T., \& Levinthal, D. A. (2007). Two faces of search: Alternative generation and alternative evaluation. Organization Science, 18(1), 39-54. doi:10.1287/orsc.1060.0216

Lazer, D., \& Friedman, A. (2007). The network structure of exploration and exploitation. Administrative Science Quarterly, 52(4), 667-694. doi:10.2189/asqu.52.4.667

Lee, S., Jang, M., \& Baek, H. (2019). Empirical Study of the Relationship between Communication-Structure Characteristics and Open Collaboration Performance: Focusing on Open-Source Software Development Platform. Journal of Information Systems, 28(1), 73-96. doi:10.5859/KAIS.2019.28.1.73

Li, D., Lin, J., Cui, W., \& Qian, Y. (2018). The trade-off between knowledge exploration and exploitation in technological innovation. Journal of Knowledge Management, 22(4), 781-801. doi:10.1108/JKM-09-2016-0401 
Liao, L., Jiang, J., \& Wang, K. (2011). Knowledge-management strategy and organizational learning: An agent-based simulation. African Journal of Business Management, 5(8), 3040-3046. doi:10.5897/AJBM09.164

March, J. G. (1991). Exploration and Exploitation in Organizational Learning. Organization Science, 2(1), 71-87. doi:10.1287/orsc.2.1.71

Martinez-Plumed, F., Ferri, C., Hernandez-Orallo, J., \& Ramirez-Quintana, M. J. (2015). Knowledge acquisition with forgetting: An incremental and developmental setting. Adaptive Behavior, 23(5), $283-299$. doi:10.1177/1059712315608675

Mason, W. A., Jones, A., \& Goldstone, R. L. (2008). Propagation of innovations in networked groups. Journal of Experimental Psychology. General, 137(3), 422-433. doi:10.1037/a0012798 PMID:18729708

Miller, K. D., \& Martignoni, D. (2016). Organizational learning with forgetting: Reconsidering the explorationexploitation tradeoff. Strategic Organization, 14(1), 53-72. doi:10.1177/1476127015608337

Miller, K. D., Zhao, M., \& Calantone, R. J. (2006). Adding interpersonal learning and tacit knowledge to March's exploration-exploitation model. Academy of Management Journal, 49(4), 709-722. doi:10.5465/ amj.2006.22083027

Moorman, C., \& Miner, A. S. (1997). The Impact of Organizational Memory on New Product Performance and Creativity. JMR, Journal of Marketing Research, 34(1), 91-106. doi:10.1177/002224379703400108

Nonaka, I. (1994). A dynamic theory of organizational knowledge creation. Organization Science, 5(1), 14-37. doi:10.1287/orsc.5.1.14

Nonaka, I., \& Takeuchi, H. (1996). The knowledge-creating company: How Japanese companies create the dynamics of innovation. Long Range Planning, 27(1), 196-201. doi:10.1057/jibs.1996.13

Nonaka, I., \& Von Krogh, G. (2009). Tacit Knowledge and Knowledge Conversion: Controversy and Advancement in Organizational Knowledge Creation Theory. Organization Science, 20(3), 635-652. doi:10.1287/orsc.1080.0412

Oh, W., Moon, J. Y., Hahn, J., \& Kim, T. (2016). Research note-Leader influence on sustained participation in online collaborative work communities: A simulation-based approach. Information Systems Research, 27(2), 383-402. doi:10.1287/isre.2016.0632

Owens, B., \& Hekman, D. (2012). Modeling How to Grow: An Inductive Examination of Humble Leader Behaviors, Outcomes, and Contingencies. Academy of Management Journal, 55(4), 787-818. doi:10.5465/ amj.2010.0441

Pham, L. M. T., Tran, L. T.-T., Thipwong, P., \& Huang, W. T. (2019). Dynamic Capability and Organizational Performance: Is Social Networking Site a Missing Link? Journal of Organizational and End User Computing, 31(2), 1-21. doi:10.4018/JOEUC.2019040101

Piller, F., \& West, J. (2014). Firms, users and innovation. An interactive model of coupled open innovation. In H. Chesbrough, W. Vanhaverbeke \& J. West (Eds.), New Frontiers in Open Innovation (pp. 29-49). Oxford University Press. doi:10.1093/acprof:oso/9780199682461.003.0002

Randhawa, K., Josserand, E., Schweitzer, J., \& Logue, D. (2017). Knowledge collaboration between organizations and online communities: The role of open innovation intermediaries. Journal of Knowledge Management, 21(6), 1293-1318. doi:10.1108/JKM-09-2016-0423

Saki, S., Shakiba, H., \& Savari, M. (2013). Study of the Relationship between the Organizational Learning and Organizational Innovation at University of Tehran. Journal of Organizational Learning \& Leadership, 11(1), 1-18.

Sanz-Valle, R., Naranjo-Valencia, J. C., Jimenez-Jimenez, D., \& Perez-Caballero, L. (2011). Linking organizational learning with technical innovation and organizational culture. Journal of Knowledge Management, 15(6), 997-1015. doi:10.1108/13673271111179334

Schilling, M. A., \& Fang, C. (2014). When Hubs Forget, Lie, and Play Favorites: Interpersonal Network Structure, Information Distortion, and Organizational Learning. Strategic Management Journal, 35(7), 974-994. doi:10.1002/smj.2142

Secchi, D., \& Gullekson, N. L. (2016). Individual and organizational conditions for the emergence and evolution of bandwagons. Computational \& Mathematical Organization Theory, 22(1), 88-133. doi:10.1007/s10588-015-9199-4 
Sharpanskykh, A., \& Stroeve, S. H. (2011). An agent-based approach for structured modeling, analysis and improvement of safety culture. Computational \& Mathematical Organization Theory, 17(1), 77-117. doi:10.1007/ s10588-011-9083-9

Sun, P. Y. T., \& Anderson, M. H. (2012). The combined influence of top and middle management leadership styles on absorptive capacity. Management Learning, 43(1), 25-51. doi:10.1177/1350507611405116

Uotila, J. (2013). Exploration, exploitation, and variability: Competition for primacy revisited. Strategic Organization, 15(4), 461-480. doi:10.1177/1476127017705103

Waddell, A., \& Pio, E. (2015). The influence of senior leaders on organisational learning: Insights from the employees' perspective. Management Learning, 46(4), 461-478. doi:10.1177/1350507614541201

West, J., Salter, A., Vanhaverbeke, W., \& Chesbrough, H. (2014). Open innovation: The next decade. Research Policy, 43(5), 805-811. doi:10.1016/j.respol.2014.03.001

Wong, S. S. (2008). Task knowledge overlap and knowledge variety: The role of advice network structures and impact on group effectiveness. Journal of Organizational Behavior, 29(5), 591-614. doi:10.1002/job.490

Wu, W., Ma, S., Wang, K., Tsai, S.-B., \& Lin, W.-P. (2019). Entrepreneurial Team Learning, Forgetting and Knowledge Levels in Business Incubators: An Exploration and Exploitation Perspective. Journal of Artificial Societies and Social Simulation, 22(1), 10. doi:10.18564/jasss.3932

Xiong, H., Payne, D., \& Kinsella, S. (2016). Peer effects in the diffusion of innovations: Theory and simulation. Journal of Behavioral and Experimental Economics, 63, 1-13. doi:10.1016/j.socec.2016.04.017

Xu, B., Liu, R., \& Liu, W. (2014). Individual bias and organizational objectivity: An agent-based simulation. Journal of Artificial Societies and Social Simulation, 17(2), 2. doi:10.18564/jasss.2426

Zablith, F., Faraj, S., \& Azad, B. (2016). Organizational knowledge generation: Lessons from online communities. Business Process Management Journal, 22(1), 33-55. doi:10.1108/BPMJ-04-2015-0047

Zhang, H., \& Xi, Y. (2012). Exploration and Exploitation in Parallel Problem Solving: Effect of Imitation Strategy and Network Structure. In Systems Approaches to Knowledge Management, Transfer, and Resource Development. IGI Global. doi:10.4018/978-1-4666-1782-7.ch013

Zhao, Y. B., Li, Y. A., Lee, S. H., \& Chen, L. B. (2011). Entrepreneurial Orientation, Organizational Learning, and Performance: Evidence From China. Entrepreneurship Theory and Practice, 35(2), 293-317. doi:10.1111/ j.1540-6520.2009.00359.x

Wenqing Wu is an Associate Professor of College of Management and Economics, Tianjin University. He has a Ph.D. in School of Management from the Tianjin University, and his research interests are in innovation and entrepreneurship. $\mathrm{He}$ is the Vice Dean of the Xuanhuai School, Tianjin University. His work has been published in a number of different journals. He has published in Scientometrics, Journal of Artificial Societies and Social Simulation, Journal of Organizational and End User Computing, Journal of Entrepreneurship in Emerging Economies, and other leading Chinese journals.

Saixiang Ma received the M. S. degree in College of Management and Economics of Tianjin University of China in 2018. His research interests include knowledge management, innovation and entrepreneurship management, technology economy and management, etc.

Yuzheng Su, Corresponding Author, is a graduate student in College of Management and Economics, Tianjin University. Her major is business administration and her main research areas include knowledge management, innovation and entrepreneurship.

Chia-Huei Wu, Corresponding Author, is currently an Assistant Professor at Institute of Service Industries and Management, Minghsin University of Science and Technology in Taiwan. She received Ph.D. degree in Technology Management from University of Chung Hua. Dr. Wu has well over 30 published peer-reviewed journal articles. Her recent research interests in Service Management, Marketing Management, Consumer Behavior and E-commerce. She is serving on the editorial boards of some journals. 